\title{
The Scope and Limitations of Intramolecular Nicholas and Pauson-Khand Reactions for the Synthesis of Tricyclic Oxygen- and Nitrogen- Containing Heterocycles
}

Kristina D. Closser

Miriam M. Quintal

Kevin M. Shea

Smith College, kshea@smith.edu

Follow this and additional works at: https://scholarworks.smith.edu/chm_facpubs

Part of the Chemistry Commons

\section{Recommended Citation}

Closser, Kristina D.; Quintal, Miriam M.; and Shea, Kevin M., "The Scope and Limitations of Intramolecular Nicholas and PausonKhand Reactions for the Synthesis of Tricyclic Oxygen- and Nitrogen-Containing Heterocycles" (2009). Chemistry: Faculty Publications, Smith College, Northampton, MA.

https://scholarworks.smith.edu/chm_facpubs/8 


\title{
The Scope and Limitations of Intramolecular Nicholas
}

\author{
and Pauson-Khand Reactions for the Synthesis of \\ Tricyclic Oxygen- and Nitrogen-Containing \\ Heterocycles
}

Kristina D. Closser, Miriam M. Quintal, and Kevin M. Shea*

Department of Chemistry, Smith College, Northampton, MA 01063

kshea@email.smith.edu

RECEIVED DATE (to be automatically inserted after your manuscript is accepted if required according to the journal that you are submitting your paper to)

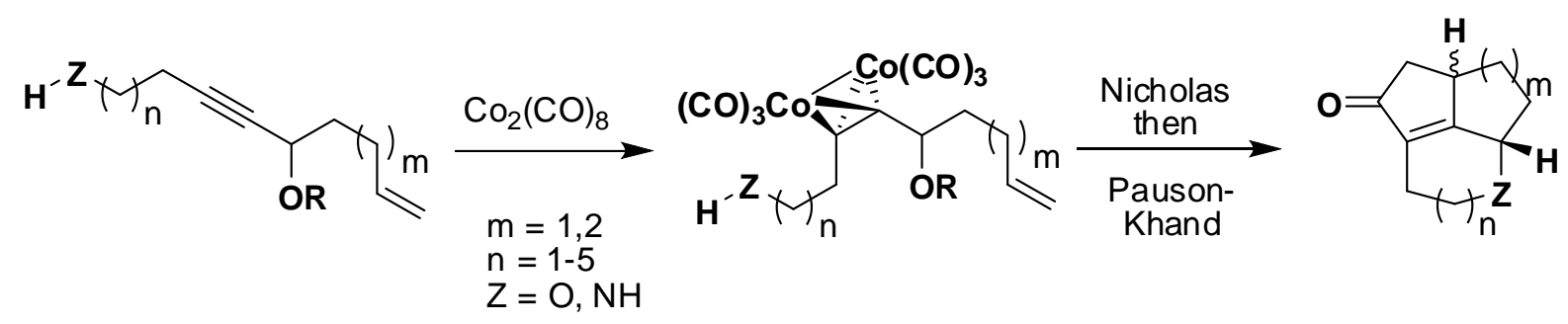

We studied the scope and limitations of a tandem intramolecular Nicholas/Pauson-Khand strategy for the synthesis of tricyclic oxygen- and nitrogen-containing heterocycles. This methodology enables conversion of simple acyclic starting materials into a series of previously unknown heterocyclic architectures. For the preparation of cyclic ethers $(\mathrm{Z}=\mathrm{O})$, tricyclic [5,6,5]- through $[5,9,5]$-systems $(\mathrm{m}$ 
$=1, \mathrm{n}=1-4)$ are available with the $[5,7,5]$ - and $[5,8,5]$-systems amenable to quick and efficient synthesis. Tricyclic $[5,7,5]$ - and $[5,8,5]$-amine-containing $(\mathrm{Z}=\mathrm{NH})$ heterocycles can be successfully prepared. Attempts to make larger-ring systems $(\mathrm{Z}=\mathrm{O}, \mathrm{m}=2 ; \mathrm{Z}=\mathrm{O}, \mathrm{n}=5$; or $\mathrm{Z}=\mathrm{NH}, \mathrm{n}=4-5)$ or prepare lactones via Nicholas reactions with carboxylic acid nucleophiles (available via oxidation of alcohol nucleophiles, $\mathrm{Z}=\mathrm{O}$ ) result in decomposition or dimerization. The latter process enables formation of 14-, 16-, and 18-membered ring diolides when using carboxylic acid nucleophiles. We also investigated the use of chiral amine promoters in the Pauson-Khand step but found no asymmetric induction.

\section{Introduction}

Methods that enable the quick and efficient conversion of simple acyclic molecules into complex polycyclic structures are highly prized in organic chemistry. ${ }^{1}$ One such strategy is the combination of an intramolecular Nicholas reaction followed by an intramolecular Pauson-Khand reaction. ${ }^{2}$ Surprisingly, this reaction sequence was not well known at the outset of our investigations. The lone application of this strategy is in Schreiber and Jamison's synthesis of epoxydictymene in which an intramolecular endocyclic Nicholas reaction with an allylsilane nucleophile is followed by an intramolecular PausonKhand reaction to provide the carbon skeleton of the target natural product. ${ }^{3}$ Beyond this example, nothing was known about the scope of this reaction sequence with respect to the nature of the nucleophile in the Nicholas reaction, the size of the ring generated in the Nicholas reaction, and the size of the rings generated in the Pauson-Khand reaction. Thus, we set out to systematically address all of these issues. $^{4}$

The overall goal of our investigation is depicted in Scheme 1. We planned to quickly generate simple, acyclic enynes 1 that, upon reaction with dicobalt octacarbonyl, would yield cobalt-alkyne complexes 2. Subsequent intramolecular Nicholas reactions would provide heterocycles $\mathbf{3}$ and, ultimately, target tricycles 4 after the Pauson-Khand reaction. Our specific goals were the following: 1) investigate alcohols $(\mathrm{Z}=\mathrm{O})$, amines $(\mathrm{Z}=\mathrm{NH})$, and carboxylic acids (available via oxidation of alcohol 
nucleophiles, $\mathrm{Z}=\mathrm{O}$ ) as nucleophiles in intramolecular Nicholas reactions; 2) determine what sized rings $(n=1-5)$ could be prepared in endocyclic intramolecular Nicholas reactions; 3$)$ study the synthesis of differently sized rings $(m=1,2)$ in the Pauson-Khand reaction. During the course of our investigations, we successfully achieved all of these goals.

Scheme 1. Overall Goal: Tandem Nicholas/Pauson-Khand Reactions for the Synthesis of Tricyclic Heterocycles
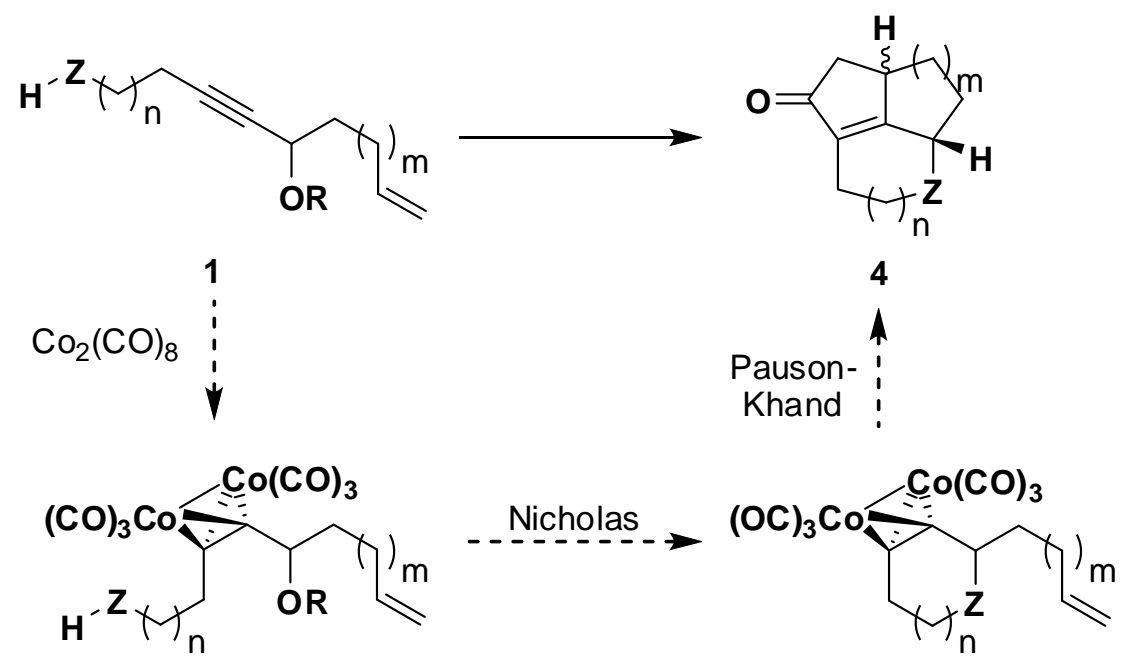

2

3

The Nicholas reaction is a highly useful inter- or intramolecular propargylic substitution reaction. Intermolecular reactions with a variety of nucleophiles are well studied, and the most common intramolecular variations involve exocyclic cyclizations with carbon nucleophiles. Intramolecular Nicholas reactions are classified as exocyclic when the cobalt-complexed alkyne ends up outside of the newly generated ring, while endocyclic cyclizations include the cobalt-alkyne complex in the newly formed ring. Of the three types of Nicholas reactions (intermolecular, exocyclic intramolecular, and endocyclic intramolecular), the endocyclic intramolecular variety is the least studied. Furthermore, use of heteroatom nucleophiles in these transformations is even less common. ${ }^{5}$ When thinking about intramolecular Nicholas reactions, it is important to note that the alkyne geometry is significantly altered upon complexation with cobalt. The standard $180^{\circ}$ bond angle is reduced to $138^{\circ}$ in these 
organometallic clusters. ${ }^{6}$ In fact, several groups have taken advantage of this change in geometry to promote intramolecular cycloaddition reactions that were initially unfavorable due to the linear alkyne geometry. $^{7}$ Thanks to Isobe's pioneering investigations into the total synthesis of ciguatoxin, there are several examples of the use of alcohol nucleophiles in endocyclic intramolecular Nicholas reactions. ${ }^{8,9}$ On the other hand, endocyclic cyclizations with amine nucleophiles are unknown, ${ }^{5,10}$ and only one report of an intermolecular Nicholas reaction with a carboxylic acid ${ }^{11}$ existed at the outset of our research. ${ }^{12}$

Intramolecular Pauson-Khand reactions for the synthesis of bicyclic carbocycles are well known. We anticipated little difficulty preparing bicyclic $[5,5]-,[5,6]-$, and $[5,7]$-systems based on the wealth of literature precedent for their construction. ${ }^{2,13}$

\section{Results and Discussion}

Our initial synthetic efforts focused on the preparation of $[5,6,5]$ - through $[5,10,5]$-tricyclic ethers. Thus, keeping $\mathrm{m}=1$ and $\mathrm{Z}=\mathrm{O}$ (Scheme 1 ), we planned to vary $\mathrm{n}$ from 1 to 5 . This would enable investigation of endocyclic intramolecular Nicholas reactions for the synthesis of 6- through 10membered ethers followed by Pauson-Khand reactions to form the final two five-membered rings in our tricyclic targets. The enynes 1 needed for the preparation of the 6 - through 8 -membered ring cyclic ethers are available in four synthetic steps starting with 4-pentenal and the appropriately sized terminal alkyne alcohol with the key transformation being an acetylide addition to 4-pentenal. ${ }^{4 a}$

Preparation of the tricyclic $[5,6,5]$-system identified the limitations of our method for the synthesis of small rings via the Nicholas reaction. Beginning with 3-butyn-1-ol and 4-pentenal, enyne 5 is available in four steps and $43 \%$ overall yield. Cobalt complexation proceeds smoothly to afford cobalt-alkyne complex 6. Not surprisingly, the subsequent Nicholas and Pauson-Khand reactions are highly inefficient. The strain inherent in rings of six or fewer members containing a cobalt-complexed alkyne, like 7, (ideal $\mathrm{C}-\mathrm{C}$ bond angles $=138^{\circ}$ ) makes them exceedingly difficult to prepare, ${ }^{14}$ and we observed mainly decomposition of the cobalt-complexed starting material during the course of this reaction. The tetrasubstituted alkene generated in the Pauson-Khand reaction $(\mathbf{7} \rightarrow \mathbf{8}+\mathbf{9})$ is also strained, thus 
explaining the disappointing yield for this transformation. This series of reactions clearly demonstrates that $[5,6,5]$-tricyclic systems are not amenable to efficient production via an intramolecular Nicholas/Pauson-Khand strategy.

Scheme 2. Synthesis of $[5,6,5]$-Tricyclic Ethers

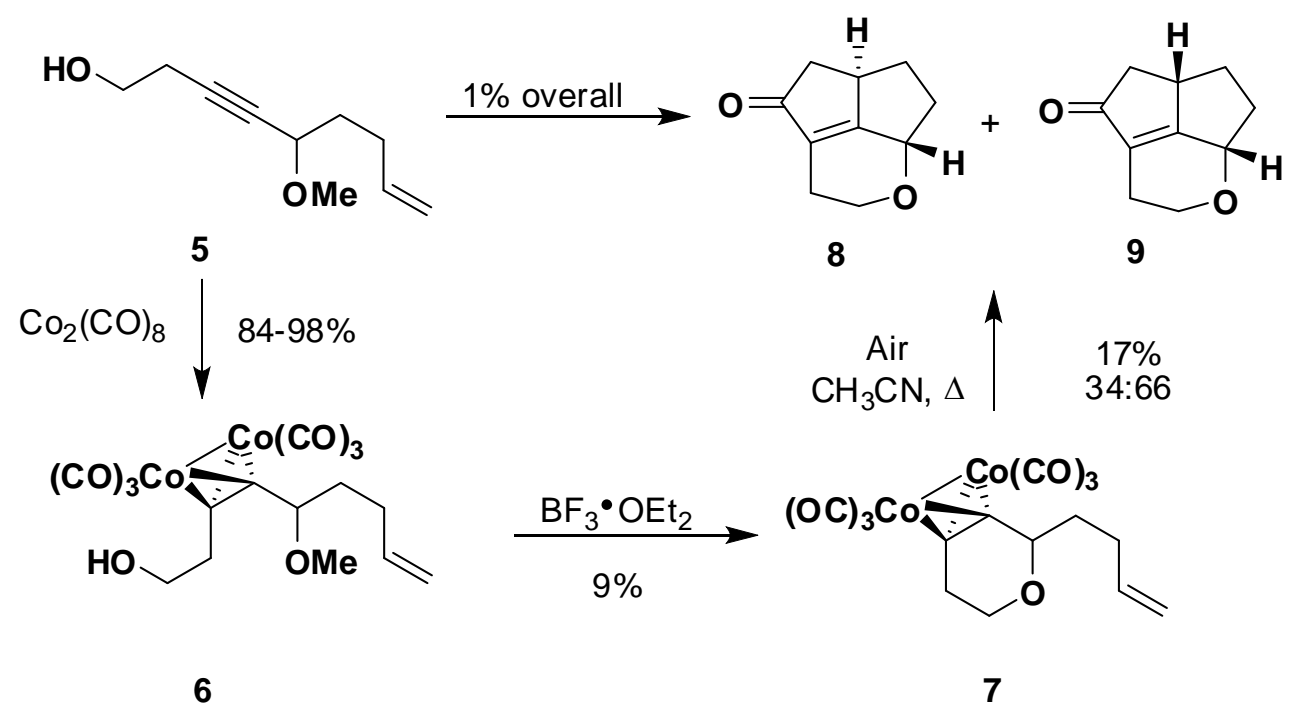

Based on literature precedent from Isobe's lab, ${ }^{8,15}$ we were optimistic that larger rings could more easily accommodate the geometrical demands of cobalt-alkyne complexes. Synthesis of the $[5,7,5]-$ tricyclic ethers $\mathbf{1 3}$ and $\mathbf{1 4}$ provided strong support for this hypothesis. Enyne $\mathbf{1 0}$ can be synthesized in four steps (28\% overall) from 4-pentyn-1-ol and 4-pentenal. ${ }^{4 a}$ Cobalt complexation to yield $\mathbf{1 1}$ is followed by a high-yielding Nicholas reaction to furnish 7-membered ring cyclic ether $\mathbf{1 2}$. We investigated several promoters in the Pauson-Khand step with $\mathrm{NMO}^{16}$ providing $\mathbf{1 3}$ and $\mathbf{1 4}$ in $30 \%$ yield (72:28) and cyclohexylamine ${ }^{17}$ generating 13 and $\mathbf{1 4}$ in 91\% yield (42:58)..$^{18,19}$ 
Scheme 3. Synthesis of [5,7,5]-Tricyclic Ethers

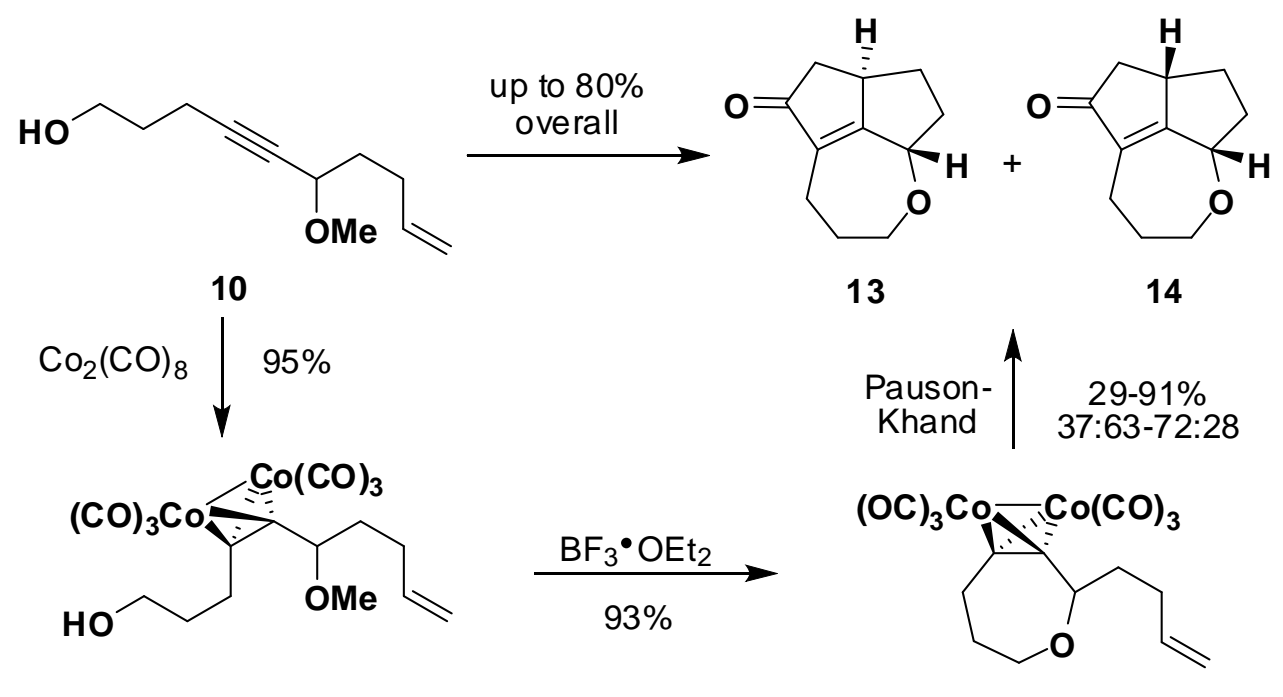

11

12

The [5,8,5]-tricyclic ethers $\mathbf{1 8}$ and $\mathbf{1 9}$ can also be prepared quickly and efficiently. Enyne $\mathbf{1 5}$, available in four steps and 54\% overall yield from 5-hexyn-1-ol and 4-pentenal, ${ }^{4 a}$ reacts with dicobalt octacarbonyl to afford cobalt-complexed alkyne $\mathbf{1 6}$ in $98 \%$ yield. The boron trifluoride mediated Nicholas reaction provides eight-membered ring cyclic ether 17 in excellent yield, and the PausonKhand reaction furnishes tricycles 18 and 19 in yields ranging from 25-86\% and selectivities of 55:4589:11 depending on the specific reaction conditions. ${ }^{18,19}$ 
Scheme 4. Synthesis of $[5,8,5]$-Tricyclic Ethers

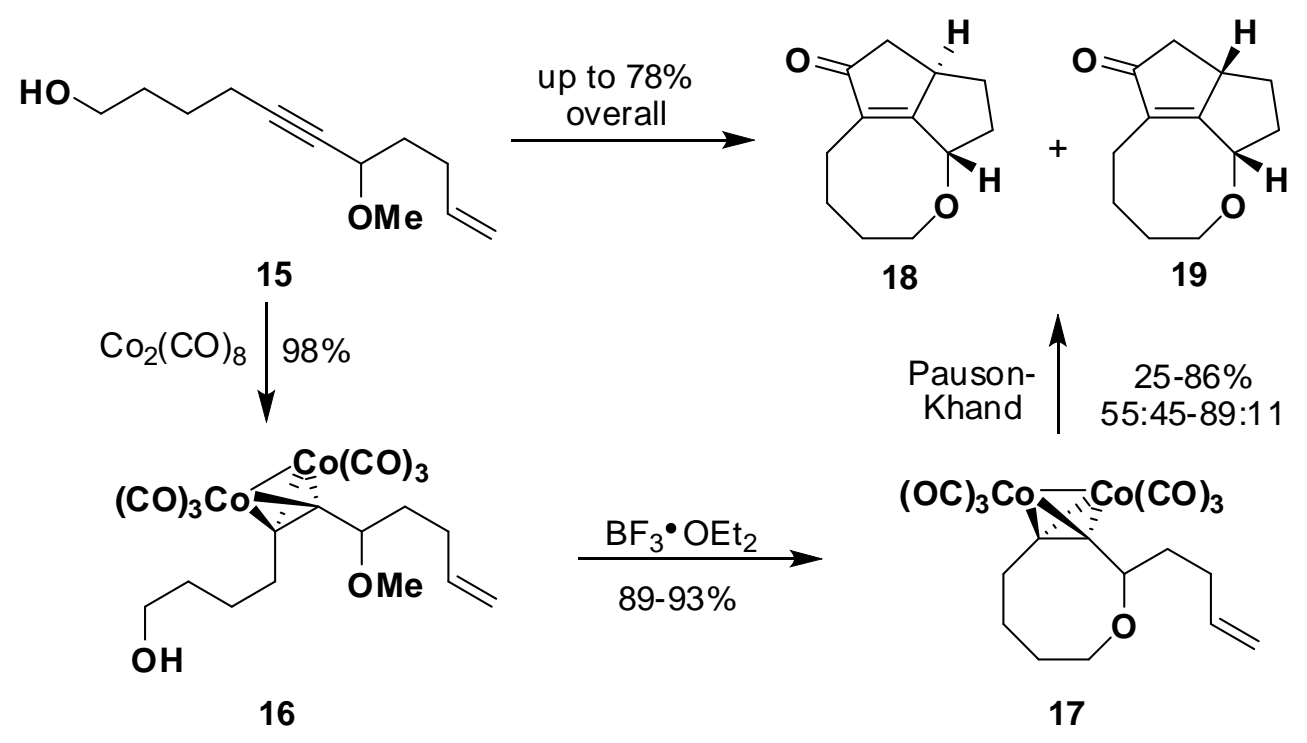

Synthesis of the $[5,9,5]$-tricyclic ether required the preparation of enyne $\mathbf{2 4}$ according to the synthetic sequence outlined in Scheme 5. Unlike the syntheses described in Schemes 2-4, the terminal alkyne starting material, 6-heptyn-1-ol (21), is prohibitively expensive. Using Denmark's procedure, ${ }^{20}$ it can be prepared by treatment of internal alkyne $\mathbf{2 0}$ with sodium hydride and ethylenediamine (EDA). Then, following the analogous procedure used for the synthesis of enynes $\mathbf{5}, \mathbf{1 0}$, and 15, enyne 24 can be generated in four more steps. Protection of the primary alcohol as the THP ether yields $\mathbf{2 2}^{21}$ which is deprotonated to provide the acetylide anion that combines with 4-pentenal to furnish alcohol 23. Methylation of the secondary alcohol with sodium hydride and methyl iodide followed by removal of the THP protecting group with PPTS yields the target enyne 24. 
Scheme 5. Synthesis of Enyne 24

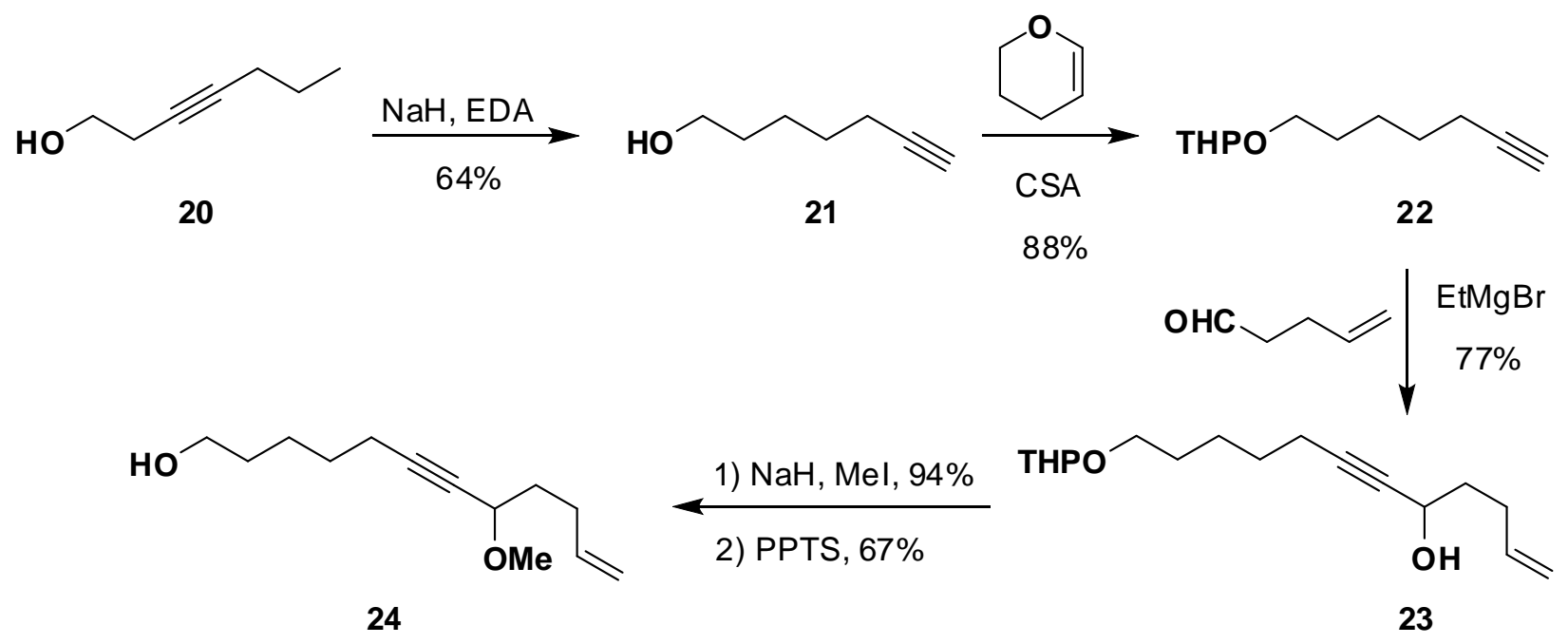

As in previous cases, cobalt complexation of $\mathbf{2 4}$ to yield $\mathbf{2 5}$ proceeded smoothly. The subsequent Nicholas reaction to form nine-membered ring ether $\mathbf{2 6}$ provided the desired compound, but only in $35-$ $52 \%$ yield. Conversion of this molecule into the tricyclic targets 27 and 28 via the Pauson-Khand reaction also proved disappointing. The reaction proceeded in only $19-27 \%$ yield; however, it was highly selective for the trans isomer. ${ }^{18}$ Of the three different conditions investigated for the PausonKhand reaction, cyclohexylamine ${ }^{17}$ failed to provide any product, heating the reaction in acetonitrile open to the air ${ }^{3}$ afforded 27 and 28 in a ratio of $91: 9$ and $19 \%$ yield, and $\mathrm{NMO}^{16}$ furnished $27 \%$ yield of 27 only. These results clearly demonstrate that, especially for the Pauson-Khand reaction, the scope for our Nicholas/Pauson-Khand strategy does not extend to a practical synthesis of $[5,9,5]$-tricyclic ethers. 
Scheme 6. Synthesis of $[5,9,5]$-Tricyclic Ethers

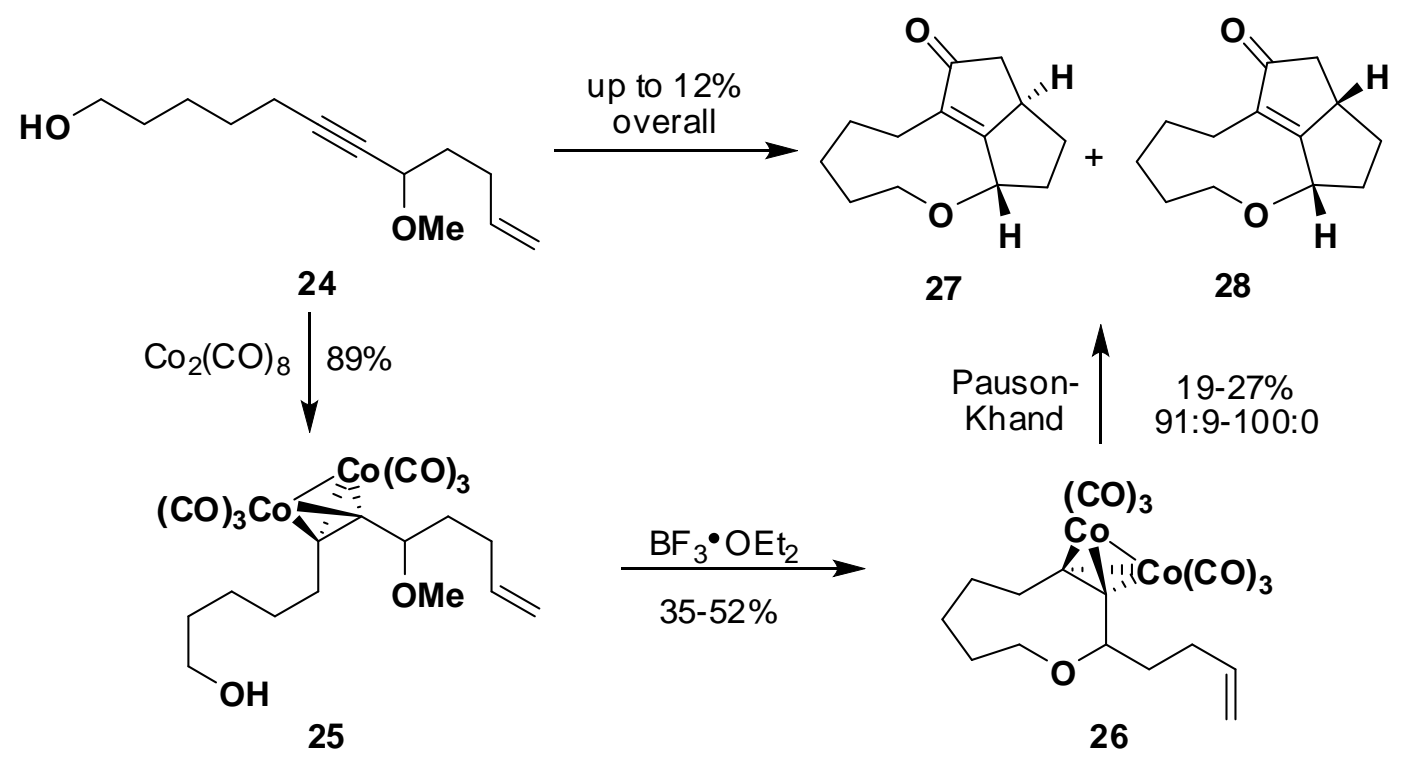

Curious to see if the trend continued for the formation of the 10 -membered ring ether, we prepared enyne 30 via the same strategy used for the preparation of the one carbon shorter enyne 24. As outlined in Scheme 7, internal alkyne $\mathbf{2 9}$ can be easily converted into target $\mathbf{3 0}$ in five synthetic steps.

Scheme 7. Synthesis of Enyne 30

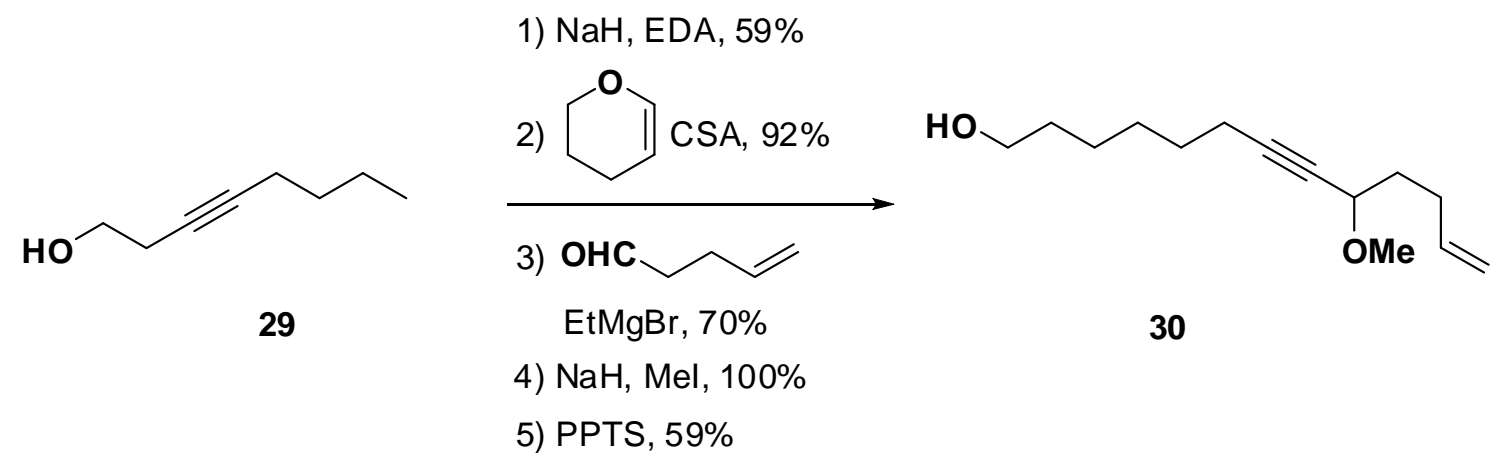

Cobalt-alkyne complex $\mathbf{3 1}$ is available in quantitative yield from enyne 30. Unexpectedly, the subsequent Nicholas reaction provided dimeric 20-membered ring bis-ether 32 instead of the desired 10membered ring cyclic ether. Since all of our Nicholas reactions are under thermodynamic control, ${ }^{15}$ this result indicates that the bis-ether is more stable than the corresponding cyclic ether. The propensity of the Nicholas reaction to favor dimerization was also demonstrated during our investigation of carboxylic 
acid nucleophiles (vide infra). Although highly inefficient, we were able to isolate the pentacyclic Pauson-Khand reaction product 33 after heating open to the air in acetonitrile. ${ }^{3}$

Scheme 8. Synthesis of 20-Membered Ring Containing Pentacyclic Dimers

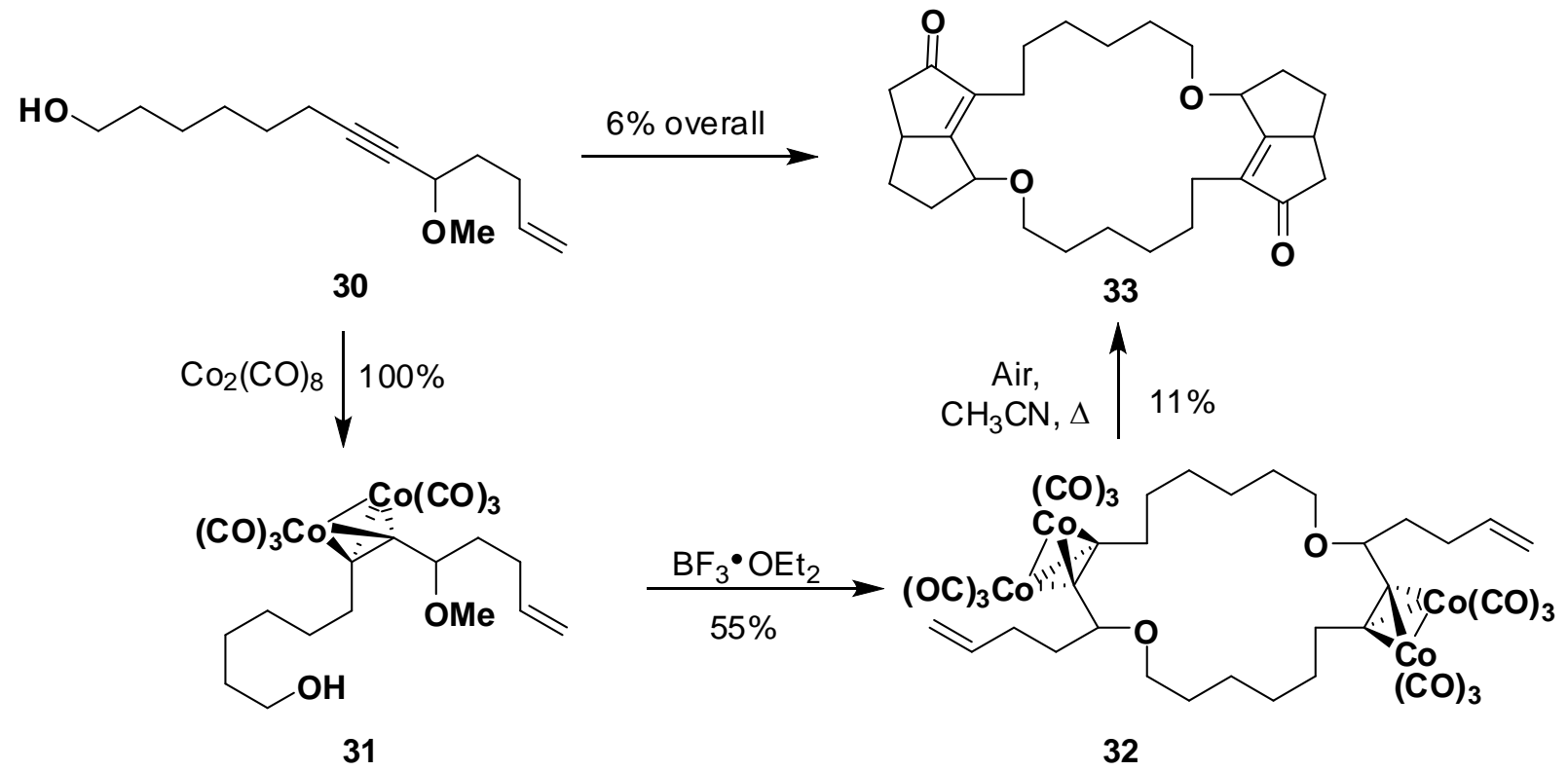

The results of our investigations into the synthesis of [5,n,5]-tricyclic ethers clearly demonstrates that the $[5,7,5]$ - and $[5,8,5]$-systems are readily available. It is possible to prepare the $[5,6,5]-$ and $[5,9,5]$ tricycles, although in poor overall yield. None of the target tricyclic [5,10,5]-ether can be isolated using our method; instead the dimeric 20-membered ring compound is produced.

We next studied the affect of enlarging one of the rings in the bicyclic system generated during the Pauson-Khand reaction. Specifically, we set our sights on the synthesis of a tricyclic [5,8,6]-system. A slight modification of our standard synthetic sequence, substitution of 5-hexenal for 4-pentenal enabled production of the starting enyne $34 .^{4 a}$ Synthesis of cobalt-alkyne complex 35 proceeded without incident; however, the key Nicholas reaction for the production of $\mathbf{3 6}$ failed. Various changes to the reaction conditions never enabled isolation of cyclic cobalt alkyne complex 36. By TLC, trace amounts of target 36 appeared to be produced, but we were never able to successfully characterize this or any 
other product of the reaction. We believe the failure of this reaction results from the distance between the alkene and the carbocation generated upon exposure of $\mathbf{3 5}$ to boron trifluoride. The alkene in the molecule is well positioned to attack the carbocation via a 5-exo or 6-endo process, thus generating a second carbocation that can participate in further polymerization or decomposition pathways. Although it may be possible to trap this carbocation with an external nucleophile, we have yet to attempt these experiments. As a consequence of our inability to synthesize 36, our subsequent investigations focused exclusively on modifications in the nature of the Nicholas reaction (structure of the nucleophile and size of the ring formed) while keeping the Pauson-Khand reaction portion of the process constant (only make $[5, n, 5]$-tricyclic systems).

Scheme 9. Attempted Synthesis of [5,8,6]-Tricyclic Ethers

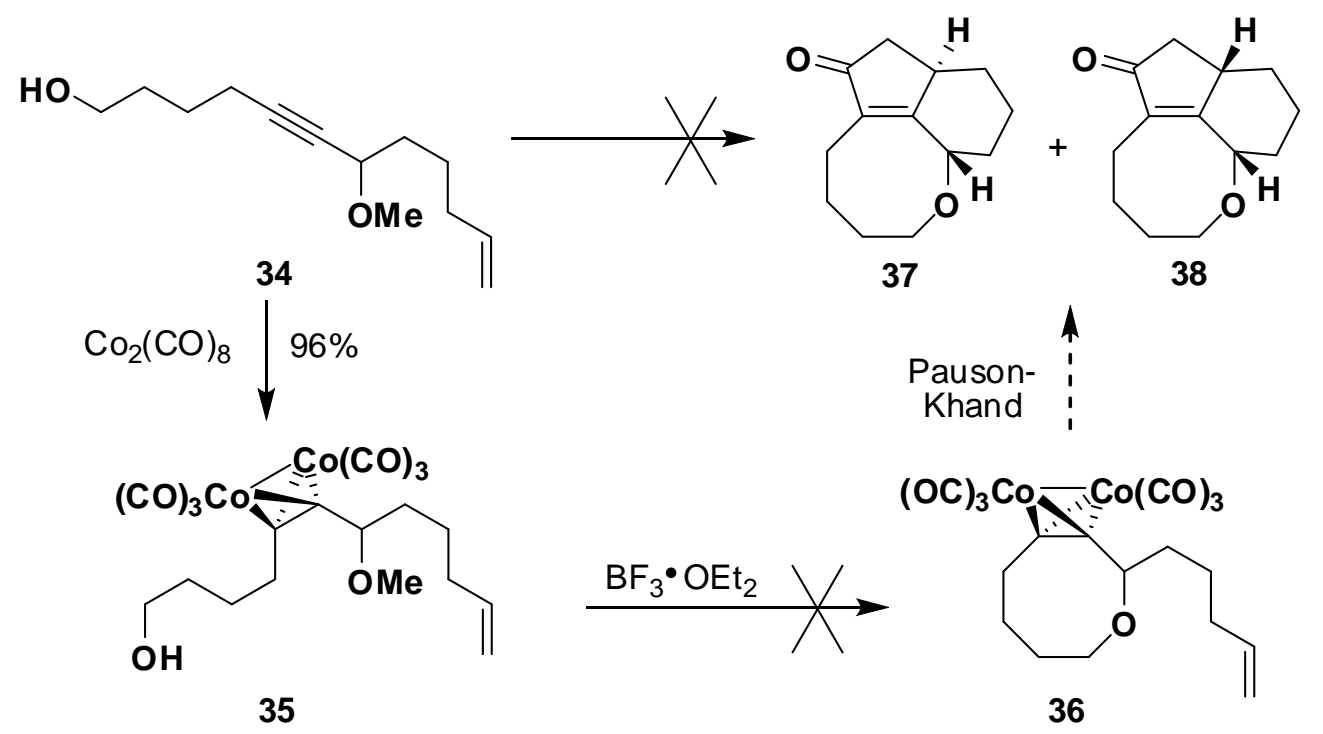

Interesting trends emerged when we focused on diastereoselectivities in the Pauson-Khand reactions for the synthesis of the cyclic ethers. As highlighted in Table 1, the diastereomeric ratios for the trans and cis isomers vary significantly for each substrate studied and reagents used. For the [5,7,5]-tricyclic ethers, two of the reagents yield the cis isomer as the major product, while the other two favor the trans. But for the $[5,8,5]$-system, all conditions favor production of the trans diastereomer. Cyclohexylamine ${ }^{17}$ 
and acetonitrile in air $^{3}$ both follow the same trends, favoring the cis isomer in the $[5,7,5]$-system and the trans isomer in the $[5,8,5]$ case. $N$-Methylmorpholine- $N$-oxide (NMO) ${ }^{16}$ and isopropyl methyl sulfide ${ }^{22}$ also appear similar, providing nearly identical ratios in both the $[5,7,5]$ - and $[5,8,5]$-systems and always favoring formation of the trans isomer.

Table 1. Selectivity in the Pauson-Khand Reaction for the Synthesis of Tricyclic Ethers

\begin{tabular}{|c|c|c|c|c|c|c|c|c|c|}
\hline \multirow{2}{*}{ Entry } & \multirow{2}{*}{ Reagents } & \multicolumn{2}{|c|}{$[5,6,5]$-Products } & \multicolumn{2}{|c|}{$[5,7,5]$-Products } & \multicolumn{2}{|c|}{$[5,8,5]$-Products } & \multicolumn{2}{|c|}{ [5,9,5]-Product } \\
\hline & & $\begin{array}{c}8 \\
\text { trans }\end{array}$ & 9 & $\begin{array}{c}13 \\
\text { trans }\end{array}$ & 14 & $\begin{array}{c}18 \\
\operatorname{trans}\end{array}$ & 19 & 27 & 28 \\
\hline 1 & $\begin{array}{c}\mathrm{CyNH}_{2}, \\
\Delta\end{array}$ & - & - & 42 & 58 & 74 & 26 & - & - \\
\hline 2 & $\begin{array}{l}\mathrm{CH}_{3} \mathrm{CN}, \\
\text { air, } \Delta\end{array}$ & 66 & 34 & 37 & 63 & 55 & 45 & 91 & 9 \\
\hline 3 & NMO & - & - & 72 & 28 & 88 & 12 & 100 & 0 \\
\hline 4 & $\begin{array}{c}i \text {-PrSMe, } \\
\Delta\end{array}$ & - & -- & 67 & 33 & 86 & 14 & - & - \\
\hline
\end{tabular}

We do not have a satisfactory explanation for the diastereoselectivity differences in the Pauson-Khand reactions of our cyclic ethers. In Scheme 10, we outline the stereochemical determining steps in the mechanism of the formation of the $[5,8,5]$ cyclic ethers $\mathbf{1 8}$ and 19. Alkene association of the free alkene to one of the cobalt atoms in $\mathbf{1 7}$ can yield either complex A or complex $\mathbf{C}$. (Note: The CO ligands in intermediates A-D have been omitted for clarity.) Complex A, with the ether oxygen in a pseudoequatorial orientation, undergoes alkene insertion to ultimately produce the trans product isomer $\mathbf{1 8}$. On the other hand, complex $\mathbf{C}$, with the ether oxygen in a pseudo-axial orientation, undergoes alkene insertion to ultimately produce the cis product isomer 19. The different Pauson-Khand promoters must influence key alkene insertion steps $(\mathbf{A} \rightarrow \mathbf{B}$ and $\mathbf{C} \rightarrow \mathbf{D})$; however, it is not clear to us how to accurately explain the results in Table 1. 
Scheme 10. Origin of Diastereoselectivity in the Pauson-Khand Reaction of Ether 17

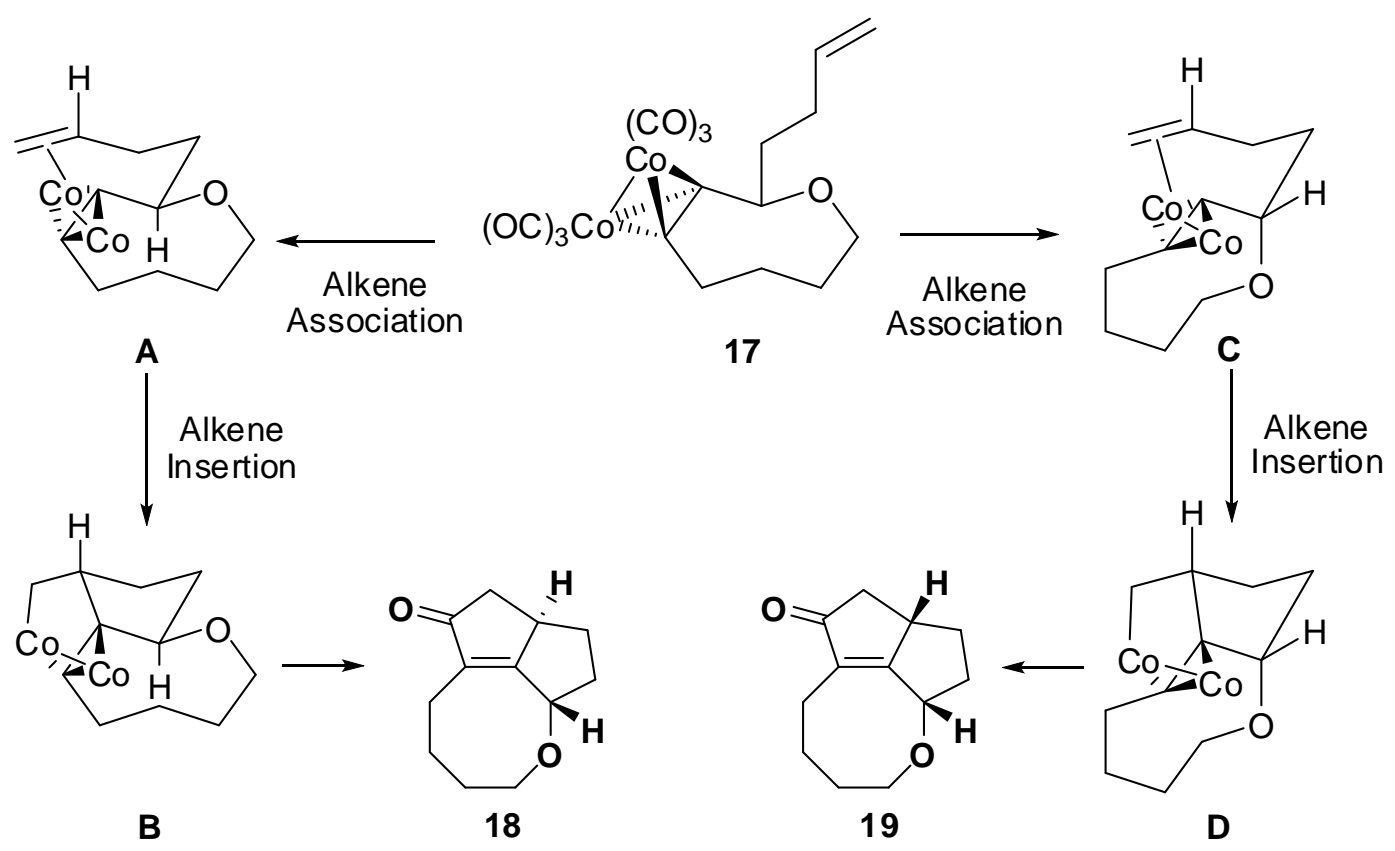

We next turned to our goal of using this strategy for the synthesis of tricyclic amines. Synthesis of the Nicholas reaction precursor 39 proved straightforward since we were able to modify the sequence previously employed for the synthesis of the [5,7,5]-tricyclic ethers by inserting a Mitsunobu reaction ${ }^{23}$ prior to the cobalt complexation step. Enyne $\mathbf{1 0}$ is converted into tosylamine $\mathbf{3 9}$ in high yield via a Mitsunobu reaction ${ }^{24}$ and exposure to dicobalt octacarbonyl. A Nicholas reaction with either boron trifluoride or tetrafluoroboric acid provides cyclic amine $\mathbf{4 0}$ in greater than $70 \%$ yield. The subsequent Pauson-Khand reaction furnishes exclusively the cis diastereomer $\mathbf{4 2}$ in excellent yield regardless of the conditions employed (cyclohexylamine, NMO, or acetonitrile and air). 
Scheme 11. Synthesis of $[5,7,5]$-Tricyclic Amines

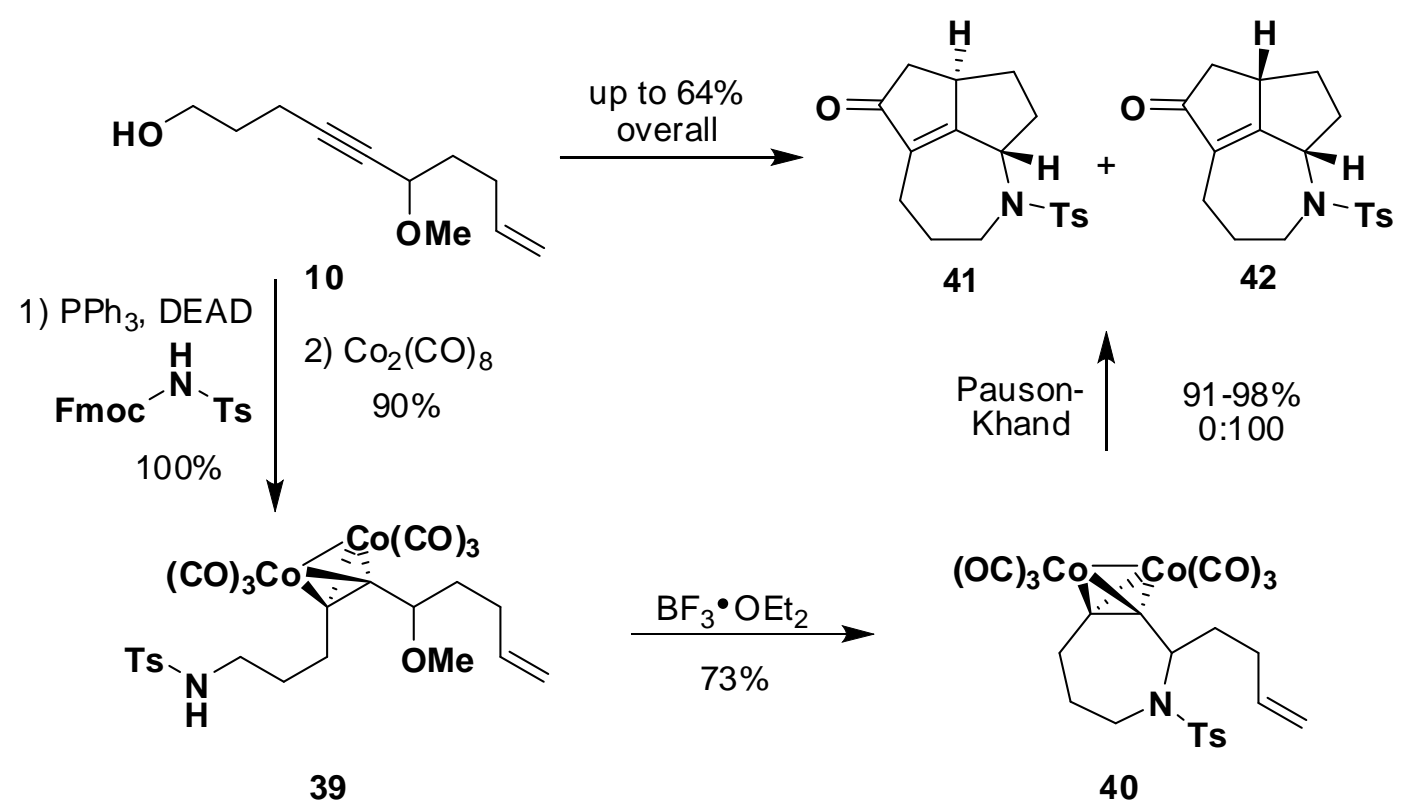

We were thrilled by the results of both the Nicholas and Pauson-Khand steps in this sequence. This is the first example of a successful endocyclic intramolecular Nicholas reaction using an amine nucleophile, and the Pauson-Khand reaction proved highly efficient and completely selective for only one isomer.

The exclusive formation of $\mathbf{4 2}$ stimulated us to consider options for an asymmetric Pauson-Khand reaction using this system. Milet and Gimbert recently published a computational study focused on the role of Lewis base promoters in the Pauson-Khand reaction in which they conclude that the Lewis base renders the olefin insertion step in the mechanism irreversible. ${ }^{25}$ In their mechanistic analysis, the amine is bound to cobalt during the entire mechanism, and, presumably, could play a crucial role in determining the stereochemical outcome of the reaction. Thus, the question we aimed to address was, could the use of chiral amine promoters generate asymmetry in the Pauson-Khand reaction? Kerr and Laschat had independently shown that chiral $N$-oxides, namely brucine $N$-oxide and sparteine $N$-oxide, respectively, could induce asymmetry in Pauson-Khand reactions solely from the asymmetric nature of the promoter. ${ }^{26}$ 
Since only one diastereomer is produced in the Pauson-Khand reaction of 40, this was the ideal substrate to investigate. However, reactions with a variety of commercially available chiral primary amines did not lead to any detectable asymmetric induction as measured by chiral GC. The amines pictured in Figure 1 led to formation of $\mathbf{4 2}$ in varying yields but always as a racemic mixture. Thus, we concluded that this idea holds no promise for our system, but we hope that others will investigate this strategy for the asymmetric Pauson-Khand reaction. This approach could provide a simple and costeffective option for the asymmetric synthesis of chiral cyclopentenones.

Figure 1. Chiral Amines Investigated as Promoters of Asymmetric Pauson-Khand Reactions<smiles>CCC(N)c1ccccc1</smiles><smiles>CCC(N)c1ccccc1</smiles><smiles>CC(N)C1CCCCC1</smiles><smiles>CC(N)C1CCCCC1</smiles><smiles>N[C@H]1CCCc2ccccc21</smiles><smiles>N[C@H]1CCCc2ccccc21</smiles>

Continuing our investigation into the synthesis of tricyclic amines, we converted enyne $\mathbf{1 5}$ into cobaltalkyne complex $\mathbf{4 3}$ after the requisite Mitsunobu reaction and cobalt complexation steps. The subsequent Nicholas reaction was successful; however, it only proceeded in $20-41 \%$ yield. The target tricycles 45 and 46 are available in 41-69\% yield using our standard Pauson-Khand reaction conditions. The selectivity for each reaction is shown in Table 2. 
Scheme 12. Synthesis of $[5,8,5]$-Tricyclic Amines

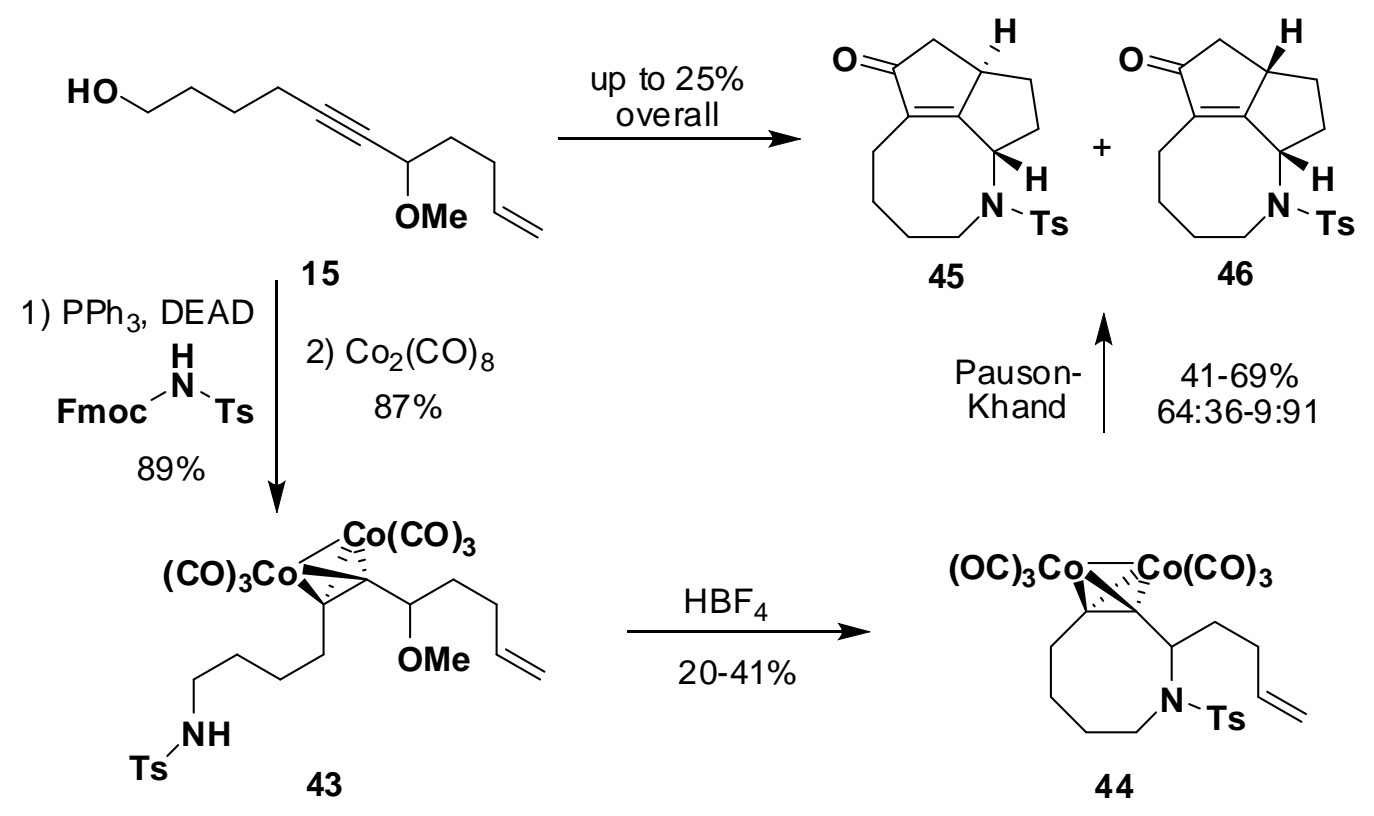

Table 2. Selectivity in the Pauson-Khand Reaction for the Synthesis of [5,8,5]-Tricyclic Amines

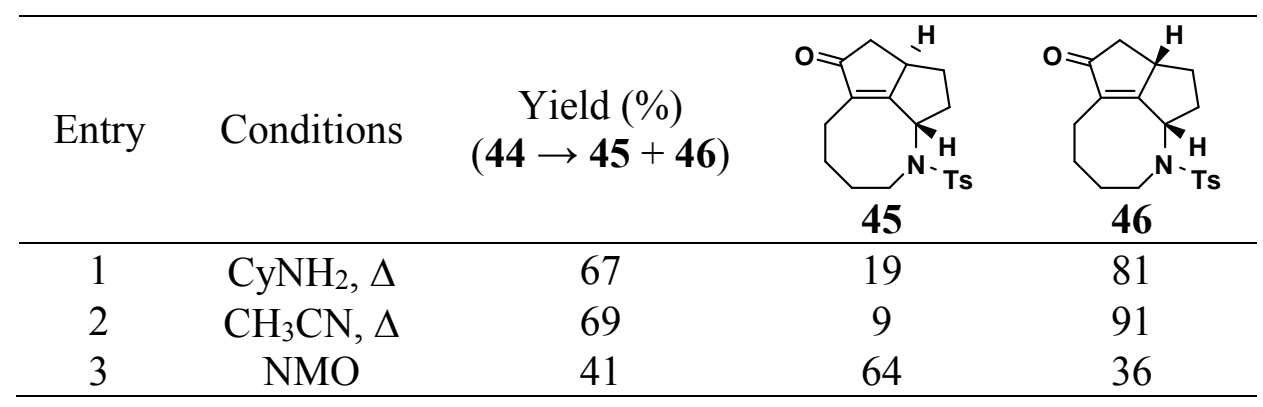

The reactions of cyclic amines $\mathbf{4 0}$ and $\mathbf{4 4}$ demonstrate the preference of these substrates to form cis diastereomers 42 and 46, respectively. In Scheme 13, the key intermediates resulting from alkene association and alkene insertion in the Pauson-Khand mechanism for the reaction of $\mathbf{4 4}$ are illustrated. The additional steric demands imposed by the tosyl group in intermediates E-H versus the corresponding oxygen-containing intermediates A-D destabilize the pathway leading to the trans cyclic amine product $\mathbf{4 5}$. Especially in the seven-membered ring cyclic amine reaction $(\mathbf{4 0} \rightarrow \mathbf{4 2}$, Scheme 11$)$, intermediates similar to $\mathbf{G}$ and $\mathbf{H}$ are favored and lead to exclusive production of the cis tricyclic product 42. 
Scheme 13. Origin of Diastereoselectivity in the Pauson-Khand Reaction of Amine 44

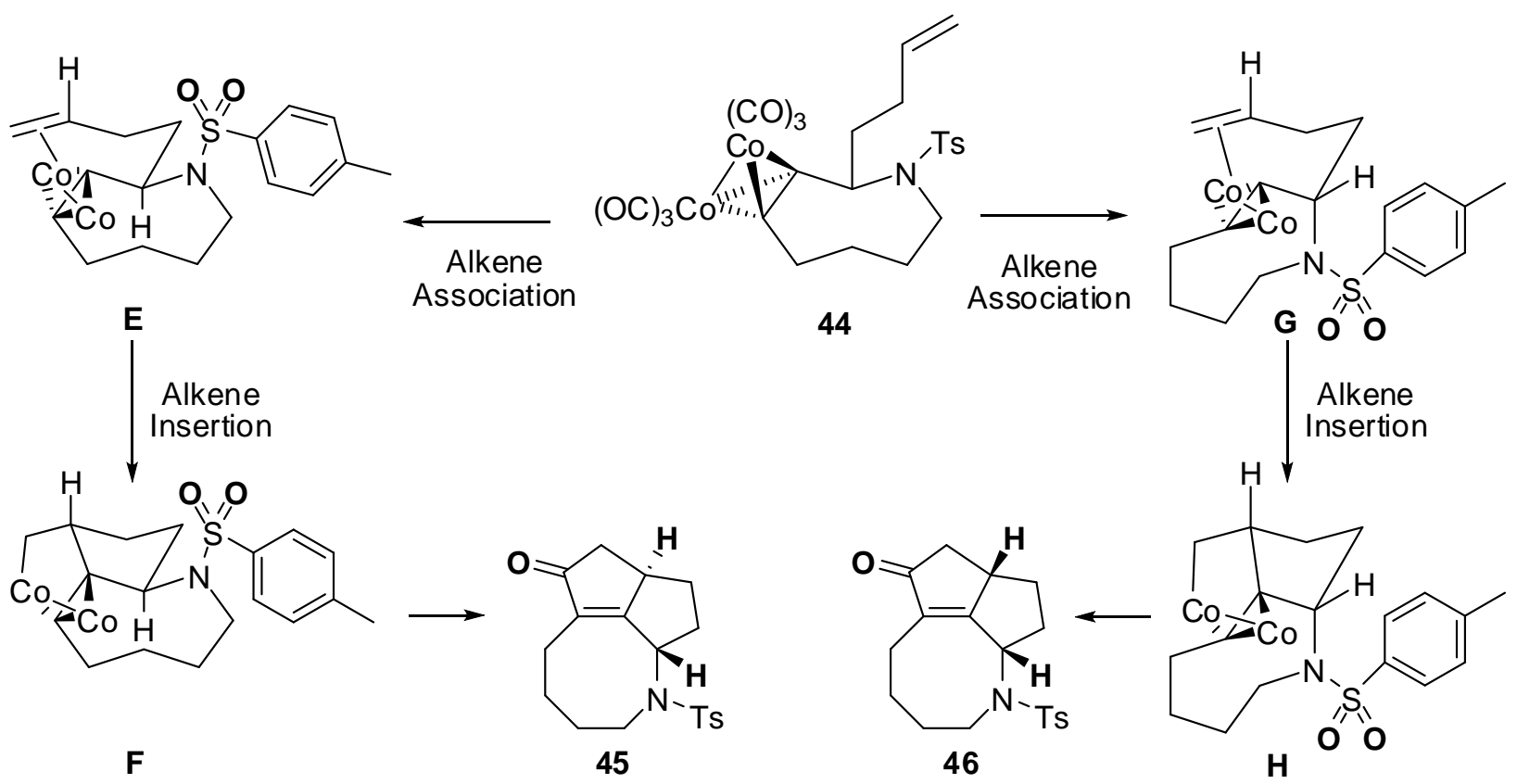

Schemes 14 and 15 illustrate our unsuccessful attempts to prepare [5,9,5]- and [5,10,5]-tricyclic amines $(\mathbf{4 9}+\mathbf{5 0}$ and $\mathbf{5 3}+\mathbf{5 4})$, respectively. In both of these cases, the requisite Nicholas reaction precursors (47 and 51) were prepared without incident. However, we could never obtain the Nicholas reaction products $\mathbf{4 8}$ or $\mathbf{5 2}$ upon exposure of the precursors to either boron trifluoride or tetrafluoroboric acid. The cobalt complexed alkynes $\mathbf{4 7}$ and $\mathbf{5 1}$ were simply unreactive under our Nicholas reaction conditions. We observed traces of the desired products by TLC but were never able to isolate enough material to adequately characterize them. We concluded that, unlike the 7- and 8-membered ring cyclic amines 40 and 44, respectively, $\mathbf{4 8}$ and $\mathbf{5 2}$ are not thermodynamically favored in these reactions. 
Scheme 14. Attempted Synthesis of [5,9,5]-Tricyclic Amines

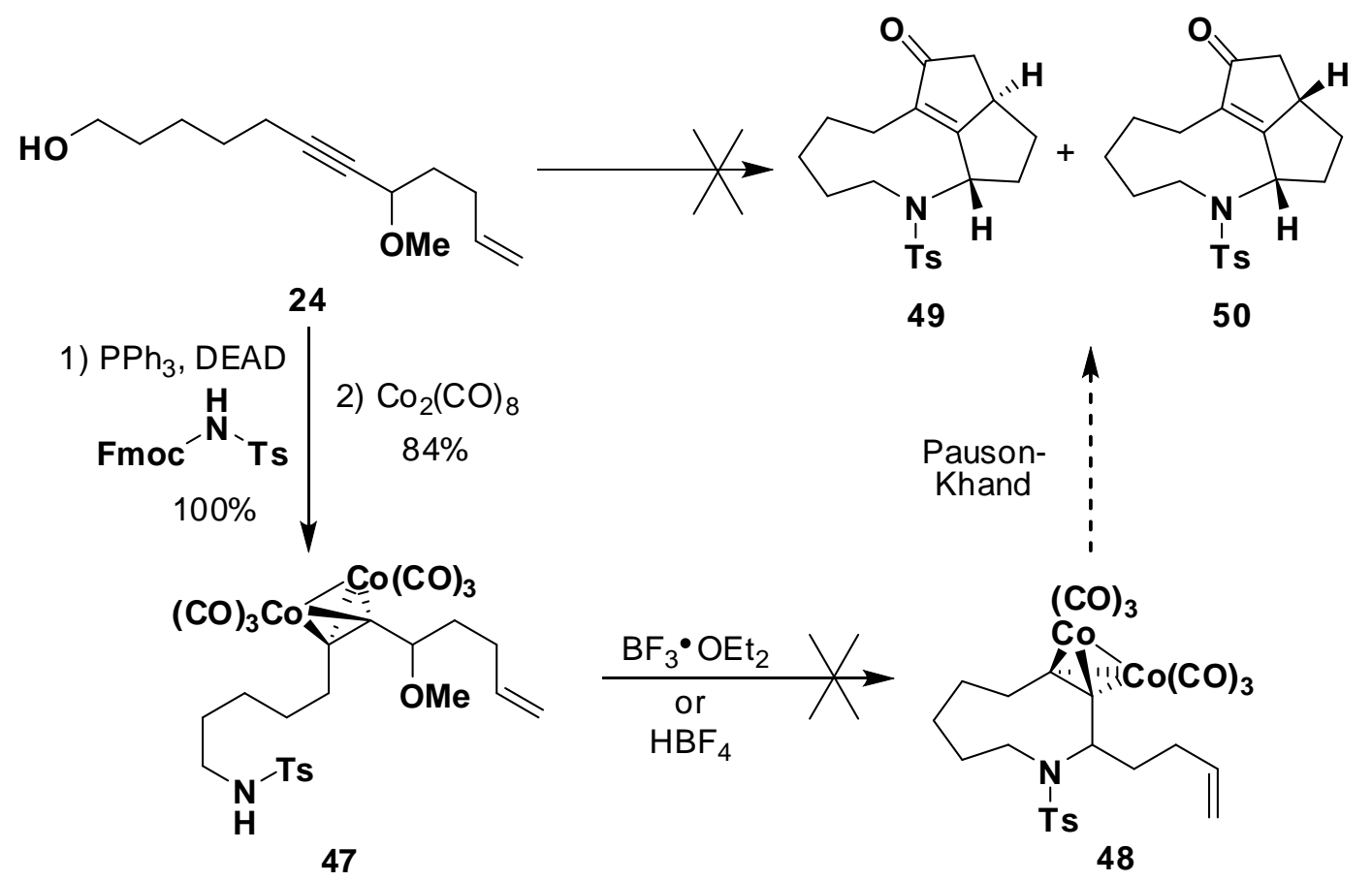

Scheme 15. Attempted Synthesis of [5,10,5]-Tricyclic Amines

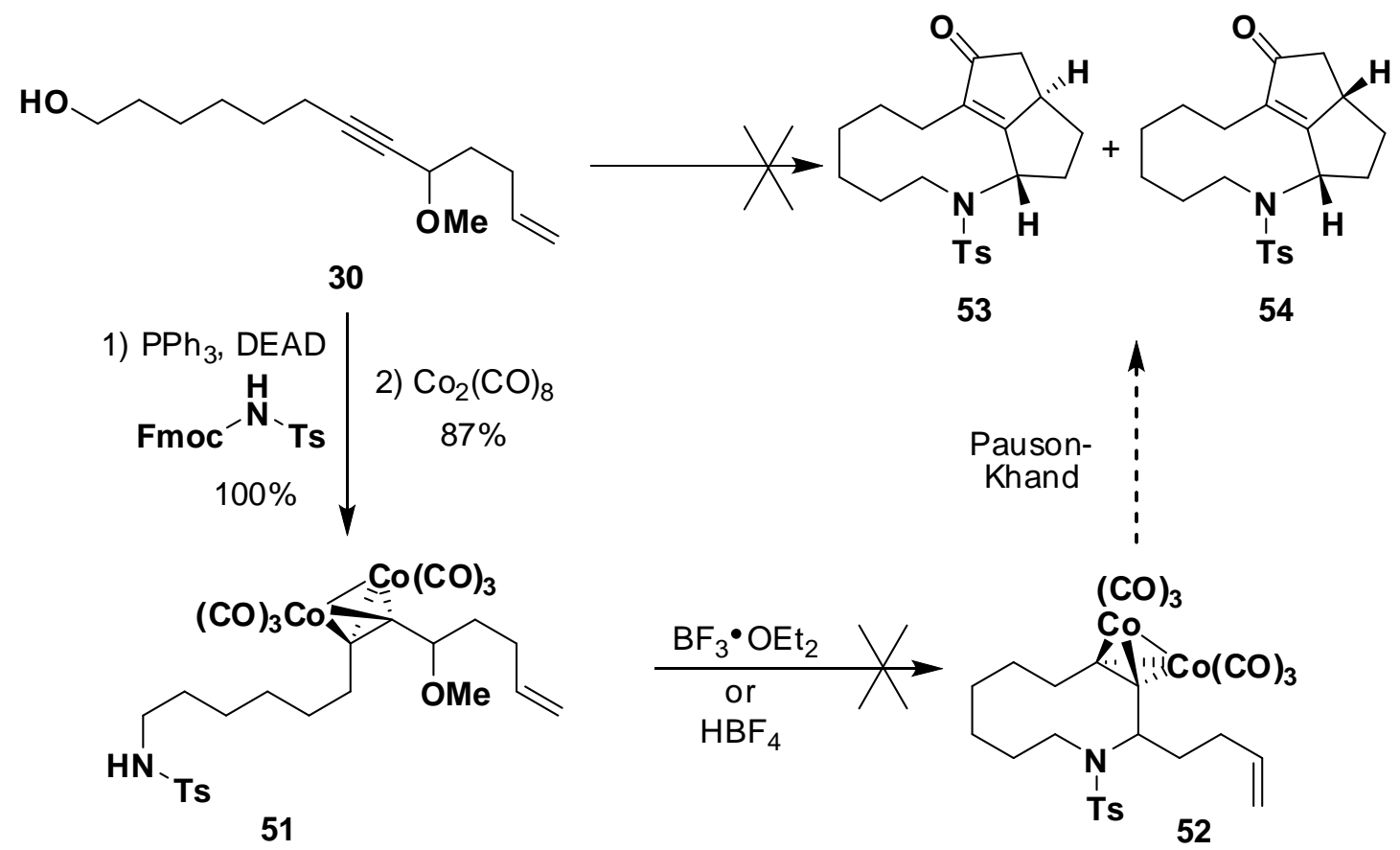


Since we were unable to obtain the 9- and 10-membered ring cyclic amines, the scope of the intramolecular Nicholas/Pauson-Khand strategy for the synthesis of cyclic amines is limited to the production of the $[5,7,5]$ - and [5,8,5]-systems. Most importantly, the tricycle containing the sevenmembered ring is available via a highly selective and efficient sequence. Thus, we have demonstrated that intramolecular endocyclic Nicholas reactions with amine nucleophiles work well for the synthesis of 7- and 8-membered rings.

Our next objective was investigation of the behavior of carboxylic acid nucleophiles in intramolecular Nicholas reactions in hopes of preparing a variety of lactones. Due to the limitations already described, we confined our experiments to the preparation of $[5,7,5]-,[5,8,5]-$, and $[5,9,5]$-tricyclic lactones.

We could easily access the substrates required for the Nicholas/Pauson-Khand investigation by simply oxidizing the starting materials used in the cyclic ether syntheses. For example, a two-step oxidation sequence involving the Dess-Martin periodinane ${ }^{27}$ followed by treatment with Oxone ${ }^{28}$ converts alcohol $\mathbf{1 0}$ into the corresponding carboxylic acid in good yield. Subsequent cobalt complexation provided the Nicholas reaction precursor 55 in $85 \%$ yield. ${ }^{29}$ The Nicholas reaction itself proved disappointing, yielding none of the desired lactone and only $18 \%$ of dimeric 14 -membered ring diolide $\mathbf{5 6}^{30}$ which did not participate in the Pauson-Khand reaction to provide 57. 
Scheme 16. Synthesis of 14-Membered Ring Diolides

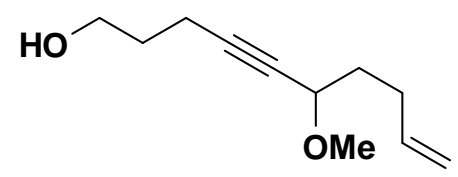

10

1) Dess-Martin, $78-81 \%$
2) Oxone, $94-95 \%$
3) $\mathrm{Co}_{2}(\mathrm{CO})_{8}, 85 \%$

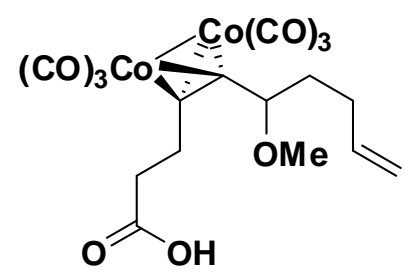

55
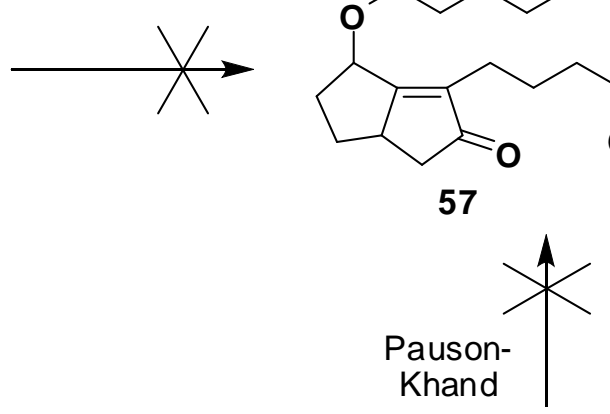

57
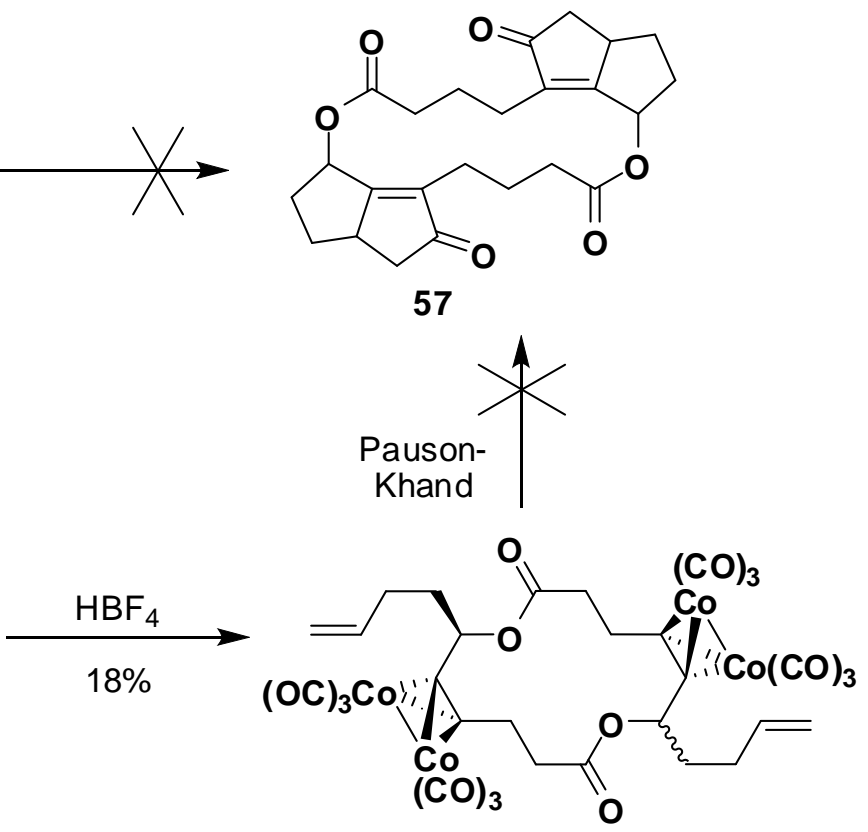

56

Substrates for the synthesis of the 8- and 9-membered ring lactones also dimerize to the 16- and 18membered ring diolides, respectively. As in the synthesis of the 14-membered ring diolide, the oxidation and cobalt complexation reactions proceed smoothly to provide high yields of the cobaltalkyne complexes 58 and 61. Upon exposure to tetrafluoroboric acid, $\mathbf{5 8}$ affords the 16-membered ring diolide $59^{31}$ in good yield, while 61 provides 18 -membered ring 62 in only $9 \%$ yield. In the reactions to form the 14-membered ring diolide 56 and the 18-membered ring diolide 62, we attribute the poor yields to a significant amount of unreacted starting material and formation of uncharacterizable byproducts. Our Nicholas reactions with carboxylic acid nucleophiles are under thermodynamic control, ${ }^{4 \mathrm{~b}}$ and these results indicate that starting materials 55 and 61 are more stable than the corresponding diolide products. Only 16-membered ring diolide 59 shows enhanced stability versus its Nicholas reaction precursor, carboxylic acid $\mathbf{5 8 .}$ 
Scheme 17. Synthesis of 16-Membered Ring Diolides

HO

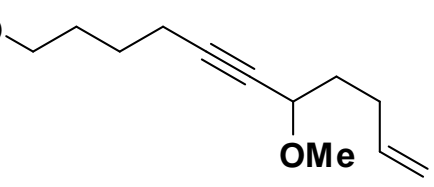

15

1) Dess-Martin, $90-97 \%$

2) Oxone, $94-96 \%$

3) $\mathrm{Co}_{2}(\mathrm{CO})_{8}, 86-97 \%$

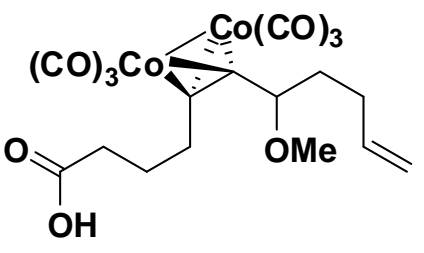

58
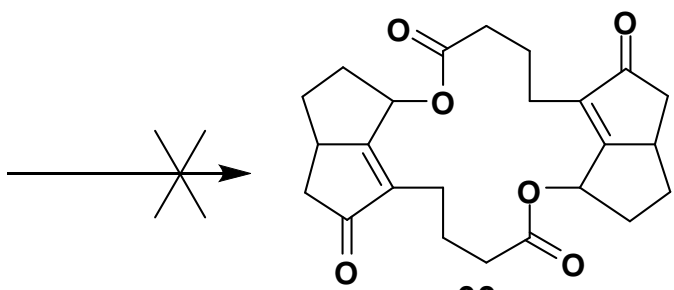

60

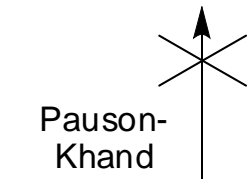

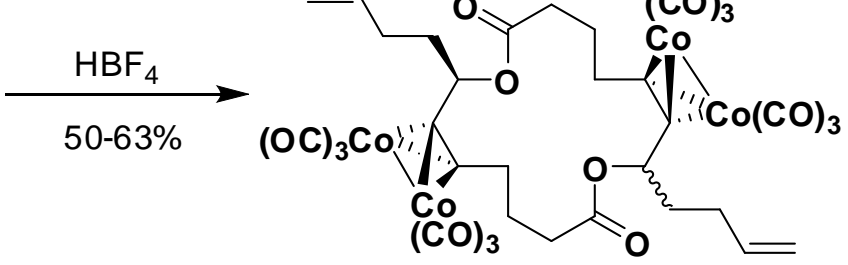

59

$81: 19$ trans:cis

Scheme 18. Synthesis of 18-Membered Ring Diolides

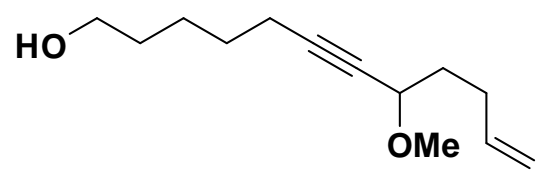

24

1) Dess-Martin, $83 \%$

2) Oxone, $100 \%$

3) $\mathrm{Co}_{2}(\mathrm{CO})_{8}, 52 \%$

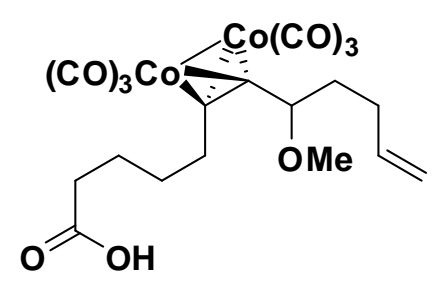

61
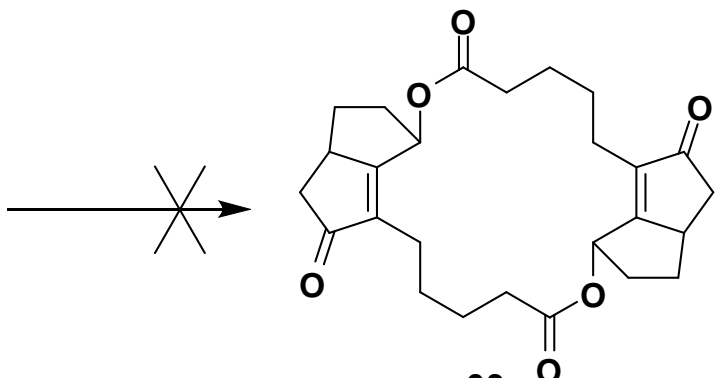

63
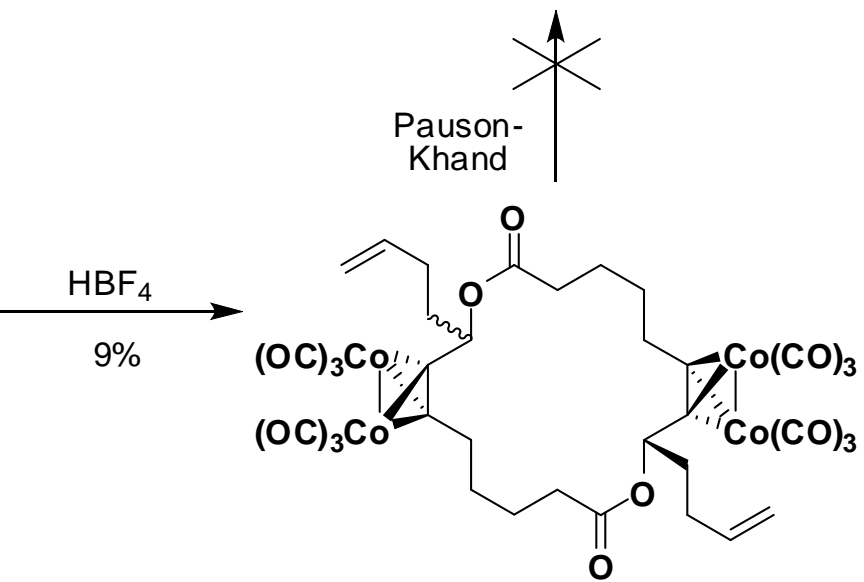

62 
As seen with diolide 56, neither 59 nor 62 participate in the Pauson-Khand reaction. We have no satisfying explanation for these surprising results. Experimentally, these reactions suffer from poor mass recovery indicating decomposition of starting material, and we have no evidence of even trace production of the desired Pauson-Khand targets. These results appear related to the Pauson-Khand reaction of 20-membered ring bis-ether 32 (Scheme 8) that proceeds in only 11\% yield. It is possible that structural constraints inherent in diolides 56, 59, and 62 do not allow proper alignment for the formation of the bicyclo[5,5] systems, whereas larger bicyclic systems (bicyclo[5,6] and bicyclo[5,7]) might form more easily.

Our investigations into the syntheses of lactones via intramolecular Nicholas reactions were unsuccessful. We observed none of the desired lactone targets in any of the three cases studied and only obtained reasonable yields for the 16-membered ring diolide. Nonetheless, the first step in the formation of our three diolides marks only the second report of an intermolecular Nicholas reaction with a carboxylic acid nucleophile, while the second step in the diolide formation constitutes the first example of an intramolecular Nicholas reaction with a carboxylic acid nucleophile. Given the known difficulties in the formation of medium sized lactone rings, ${ }^{32,33}$ it is not surprising that our method yields only diolide products. As stated previously, our Nicholas reactions are thermodynamically controlled, and the large sized diolides are clearly more stable than the target lactones.

\section{Conclusions}

In summary, we have demonstrated the scope and limitations of a tandem intramolecular Nicholas/Pauson-Khand strategy for the synthesis of tricyclic oxygen- and nitrogen-containing heterocycles. We can successfully prepare a variety of [5,n,5]-tricyclic systems; however, difficulties in the Nicholas reaction with an appropriately functionalized substrate prevented the synthesis of $[5, n, 6]-$ systems. Intramolecular Nicholas reactions with alcohol nucleophiles have broader scope than the corresponding amine or carboxylic acid nucleophiles. Our best cases were syntheses of the [5,7,5]- and 
$[5,8,5]$-tricyclic ethers and amines which demonstrated the utility of our strategy for the quick and efficient construction of complex polycyclic targets.

\section{Experimental Section}

\section{Methoxydodec-11-en-6-yn-1-ol dicobalt hexacarbonyl complex (25). A 25-mL pear flask} containing enyne 24 (159 mg, $0.76 \mathrm{mmol}, 1.0$ equiv) was equipped with a rubber septum and gas inlet needle. Dichloromethane $(2 \mathrm{~mL})$ was added, followed by dicobalt octacarbonyl $(310 \mathrm{mg}, 0.907 \mathrm{mmol}$, 1.2 equiv). The reaction was stirred for $30 \mathrm{~min}$, and a second portion of dicobalt octacarbonyl (103 $\mathrm{mg}$, 0.302 mmol, 0.4 equiv) was added. After another 30 minutes the reaction mixture was applied directly to a $38 \mathrm{~g}$ silica gel column eluted with $25-50 \%$ diethyl ether in petroleum ether to afford $334 \mathrm{mg}(89 \%)$ of 25 as a dark red oil: IR (neat) 3387, 3081, 2936, 2863, 2088, 2040, 1993, $1642 \mathrm{~cm}^{-1}$; ${ }^{1} \mathrm{H}$ NMR (400 $\left.\mathrm{MHz}_{\mathrm{CDCl}}\right) \delta 5.85(\mathrm{ddt}, J=18.5,11.9,6.6 \mathrm{~Hz}, 1 \mathrm{H}), 5.08(\mathrm{dd}, J=17.0,1.3 \mathrm{~Hz}, 1 \mathrm{H}), 5.02(\mathrm{br} \mathrm{d}, J=9.9$ $\mathrm{Hz}, 1 \mathrm{H}), 4.26(\mathrm{dd}, J=9.0,3.5 \mathrm{~Hz}, 1 \mathrm{H}), 3.68(\mathrm{q}, J=6.0 \mathrm{~Hz}, 2 \mathrm{H}), 3.52(\mathrm{~s}, 3 \mathrm{H}), 2.84(\mathrm{~m}, 2 \mathrm{H}), 2.33-2.25$ $(\mathrm{m}, 2 \mathrm{H}), 1.88-1.51(\mathrm{~m}, 7 \mathrm{H}), 1.29(\mathrm{~m}, 2 \mathrm{H}) ;{ }^{13} \mathrm{C} \mathrm{NMR}\left(100 \mathrm{MHz}, \mathrm{CDCl}_{3}\right) \delta 200.1,137.9,115.4,99.1$, $98.3,81.1,62.7,58.7,37.1,33.9,32.5,31.8,30.4,25.8$.

2-(But-3-enyl)oxon-3-yne dicobalt hexacarbonyl complex (26). A 25-mL flask containing cobaltcomplexed alkyne 25 (228 mg, $0.46 \mathrm{mmol}, 1.0$ equiv) was equipped with a rubber septum and gas inlet needle. Dichloromethane $(20 \mathrm{~mL})$ was added, the reaction flask was cooled at $0{ }^{\circ} \mathrm{C}$, and boron trifluoride diethyl etherate ( $58 \mu \mathrm{L}, 0.46 \mathrm{mmol}, 1.0$ equiv) was added. The reaction was stirred for 30 min then quenched by addition of $20 \mathrm{~mL}$ saturated sodium bicarbonate. The organic layer was removed and the aqueous layer was extracted twice with dichloromethane. The combined organic layers were dried with magnesium sulfate and added to a sintered glass funnel filled with silica gel and eluted with $10 \%$ diethyl ether in petroleum ether until the first red band was collected and concentrated to yield 91 mg (43\%) of 26 as a dark red oil: IR (neat) 3080, 2934, 2859, 2088, 2045, 2014, 1642, $1609 \mathrm{~cm}^{-1} ;{ }^{1} \mathrm{H}$ NMR (400 MHz, $\left.\mathrm{CDCl}_{3}\right) \delta 5.87(\mathrm{~m}, 1 \mathrm{H}), 5.04(\mathrm{~m}, 2 \mathrm{H}), 4.40(\mathrm{~m}, 1 \mathrm{H}), 3.97-3.46(\mathrm{~m}, 2 \mathrm{H}), 3.28-2.89(\mathrm{~m}$, 
2H), 2.40-2.20 (m, 2H), 1.93-1.53 (m, 4H), 1.32-1.18 (m, 3H), $0.87(\mathrm{~m}, 1 \mathrm{H}) ;{ }^{13} \mathrm{C}$ NMR $(100 \mathrm{MHz}$,

$\left.\mathrm{CDCl}_{3}\right) \delta 200.1,138.2,115.3,37.8,34.8,31.7,30.4,30.1,29.8,29.5,27.8,25.9,25.2$.

\section{3,4,5,6,8a,9,10,10a-Octahydro-2H-pentaleno[1,6-bc]oxonin-7(8H)-one $(27+28)$.}

Acetonitrile: ${ }^{3}$ To a 25-mL round-bottomed flask containing cobalt complexed alkyne 26 (132 mg, 0.28 mmol, 1.0 equiv) was added acetonitrile $(27 \mathrm{~mL})$. The flask was equipped with a reflux condenser, left open to the air, and heated at reflux $\left(100^{\circ} \mathrm{C}\right)$ for $20 \mathrm{~min}$. The reaction mixture was then cooled to room temperature, added to a sintered glass funnel containing $5 \mathrm{~g}$ silica gel and $5 \mathrm{~g}$ celite, and rinsed with ethyl acetate. The filtrate was concentrated to yield $78 \mathrm{mg}(136 \%)$ of crude products 27 and 28 . The crude product was deposited on $150 \mathrm{mg}$ silica gel and added to a 6 g silica gel column eluted with $20 \%$ diethyl ether in petroleum ether to afford $21 \mathrm{mg}(19 \%)$ of $\mathbf{2 7}$ and $\mathbf{2 8}$ as a viscous oil with a ratio of 27:28 of $12: 1$.

$N$-methylmorpholine- $N$-oxide (NMO): ${ }^{16}$ A 50-mL three-necked flask equipped with a rubber septum, glass stopper, and gas inlet adapter was charged with the cobalt-complexed alkyne 26 (142 mg, 0.31 mmol, 1.0 equiv) and dichloromethane $(12 \mathrm{~mL})$. The flask was cooled at $0{ }^{\circ} \mathrm{C}, \mathrm{NMO}(108 \mathrm{mg}, 0.92$ mmol, 3.0 equiv) was added, and the reaction was warmed to room temperature. After 45 min, the reaction was again cooled at $0{ }^{\circ} \mathrm{C}$ and another portion of NMO (108 mg) was added. The reaction mixture was warmed to room temperature and stirred for $45 \mathrm{~min}$. This process of cooling at $0{ }^{\circ} \mathrm{C}$, adding NMO (108 mg) and stirring at room temperature for $45 \mathrm{~min}$, was repeated a third time. TLC indicated that the reaction had gone to completion so the reaction mixture was added to a sintered glass funnel filled with celite and rinsed with dichloromethane. The filtrate was washed with water and saturated sodium bicarbonate, filtered, and concentrated to yield $70 \mathrm{mg}$ (111\%) of a yellow oil. The crude product was applied neat to a $7 \mathrm{~g}$ silica gel column eluted with $25 \%$ diethyl ether in petroleum ether to afford $17 \mathrm{mg}(27 \%)$ of 27 as a colorless film: IR (neat) 2961, 2926, 2855, $1731 \mathrm{~cm}^{-1} ;{ }^{1} \mathrm{H}$ NMR $\left(400 \mathrm{MHz} \mathrm{CDCl}_{3}\right) \delta 4.38(\mathrm{t}, J=7.3 \mathrm{~Hz}, 1 \mathrm{H}), 4.08(\mathrm{dt}, J=12.4,5.3 \mathrm{~Hz}, 1 \mathrm{H}), 3.70(\mathrm{~m}, 1 \mathrm{H}), 3.01$ (br m, 1H), $2.69(\mathrm{dd}, J=17.8,6.0 \mathrm{~Hz}, 1 \mathrm{H}), 2.63(\mathrm{dt}, J=14.6,4.4 \mathrm{~Hz}, 1 \mathrm{H}), 2.50(\mathrm{~m}, 1 \mathrm{H}), 2.22-2.13(\mathrm{~m}, 2 \mathrm{H})$, 
$2.03(\mathrm{dd}, J=17.9,3.3 \mathrm{~Hz}, 1 \mathrm{H}), 1.89(\mathrm{~m}, 1 \mathrm{H}), 1.73(\mathrm{~m}, 1 \mathrm{H}), 1.65-1.51(\mathrm{~m}, 3 \mathrm{H}), 1.40(\mathrm{~m}, 2 \mathrm{H}), 1.01(\mathrm{~m}$,

$1 \mathrm{H}) ;{ }^{13} \mathrm{C} \mathrm{NMR}\left(100 \mathrm{MHz}, \mathrm{CDCl}_{3}\right) \delta 211.2,181.8,136.0,71.8,65.9,43.1,42.1,35.1,29.2,29.0,25.2$, 22.5, 19.5; HRMS-FAB $m / z[\mathrm{M}+\mathrm{H}]^{+}$calcd for $\mathrm{C}_{13} \mathrm{H}_{19} \mathrm{O}_{2} 207.1391$, found 207.1385.

N-(6-methoxydec-9-en-4-ynyl)-4-methylbenzenesulfonamide. A 50-mL two-necked flask equipped with a rubber septum and gas inlet adapter was charged with (fluorenyl)methyl tosylcarbamate ${ }^{24}$ (320 mg, $0.81 \mathrm{mmol}, 1.5$ equiv), triphenylphosphine (428 mg, $1.63 \mathrm{mmol}, 3.0$ equiv), and THF (4 mL), and cooled at $0{ }^{\circ} \mathrm{C}$. A separate $25-\mathrm{mL}$ pear flask was charged with alcohol 10 (99 $\mathrm{mg}, 0.54 \mathrm{mmol}, 1.0$ equiv) and $2 \mathrm{~mL}$ THF. This solution was transferred into the reaction flask via cannula followed by a 1 $\mathrm{mL}$ THF rinse. Diethylazadicarboxylate $(232 \mathrm{mg}, 1.36 \mathrm{mmol}, 2.5$ equiv) was added to the reaction flask, and the reaction was allowed to stir overnight. The reaction mixture was concentrated to yield $1.27 \mathrm{~g}(737 \%)$ of a yellow oil. The crude product was deposited on $4 \mathrm{~g}$ silica gel and added to a $35 \mathrm{~g}$ column eluted with $25 \%$ diethyl ether in petroleum ether to yield $206 \mathrm{mg}$ (118\%) of the target amine as a yellow oil, which was determined to be $90 \%$ pure based on the ${ }^{1} \mathrm{H}$ NMR and was used without further purification in the subsequent cobalt complexation step: IR (neat) 3283, 3073, 2822, 2976, 2249, 1748, 1640, $1598 \mathrm{~cm}^{-1} ;{ }^{1} \mathrm{H}$ NMR $\left(400 \mathrm{MHz}, \mathrm{CDCl}_{3}\right) \delta 7.72(\mathrm{dt}, J=8.4,1.8 \mathrm{~Hz}, 2 \mathrm{H}), 7.30(\mathrm{~d}, J=8.1 \mathrm{~Hz}, 2 \mathrm{H})$, $5.78(\mathrm{~m}, 1 \mathrm{H}), 5.01(\mathrm{dq}, J=17.0,1.7 \mathrm{~Hz}, 1 \mathrm{H}), 4.96(\mathrm{dm}, J=10.2 \mathrm{~Hz}, 1 \mathrm{H}), 4.53$ (br s, $1 \mathrm{H}), 3.87$ (tt, $J=6.4$, $1.9 \mathrm{~Hz}, 1 \mathrm{H}), 3.32(\mathrm{~s}, 3 \mathrm{H}), 2.42(\mathrm{~s}, 3 \mathrm{H}), 2.26(\mathrm{td}, J=7.0,1.8 \mathrm{~Hz}, 2 \mathrm{H}), 2.14(\mathrm{~m}, 2 \mathrm{H}), 1.76-1.64(\mathrm{~m}, 3 \mathrm{H})$, 1.34-1.19 (m, 3H); ${ }^{13} \mathrm{C}$ NMR $\left(100 \mathrm{MHz}, \mathrm{CDCl}_{3}\right) \delta 143.5,137.8,137.0,130.0,127.3,115.2,85.0,80.0$, $70.7,56.3,42.3,34.9,29.5,28.5,21.6,16.1$.

\section{$\mathrm{N}$-(6-methoxydec-9-en-4-ynyl)-4-methylbenzenesulfonamide dicobalt hexacarbonyl complex}

(39). A $25-\mathrm{mL}$ pear flask containing the amine resulting from Mitsunobu reaction of alcohol 10 (92 $\mathrm{mg}$, $0.28 \mathrm{mmol}, 1.0$ equiv) was equipped with a rubber septum and gas inlet needle. Dichloromethane (2 $\mathrm{mL}$ ) was added, followed by dicobalt octacarbonyl (115 mg, $0.34 \mathrm{mmol}, 1.2$ equiv). The reaction was stirred for $30 \mathrm{~min}$, and a second portion of dicobalt octacarbonyl (38 $\mathrm{mg}, 0.11 \mathrm{mmol}, 0.4$ equiv) was added. After another 30 minutes the reaction mixture was added to an $18 \mathrm{~g}$ silica gel column and eluted 
with $25 \%$ diethyl ether in petroleum ether yielded $160 \mathrm{mg}(90 \%)$ of 39 as a dark red oil: ${ }^{1} \mathrm{H}$ NMR (400 $\mathrm{MHz}_{\mathrm{CDCl}} \mathrm{CD}_{3} \mathrm{7.70}(\mathrm{d}, J=8.4 \mathrm{~Hz}, 2 \mathrm{H}), 7.30(\mathrm{~d}, J=7.7 \mathrm{~Hz}, 2 \mathrm{H}), 5.84(\mathrm{~m}, 1 \mathrm{H}), 5.04(\mathrm{~m}, 2 \mathrm{H}), 4.43(\mathrm{~m}$, 1H), $4.42(\mathrm{~m}, 1 \mathrm{H}), 3.48(\mathrm{~s}, 3 \mathrm{H}), 2.81(\mathrm{~m}, 1 \mathrm{H}), 2.43(\mathrm{~s}, 3 \mathrm{H}), 2.25(\mathrm{~m}, 2 \mathrm{H}), 1.78(\mathrm{~m}, 4 \mathrm{H}), 1.25(\mathrm{~m}, 3 \mathrm{H})$; ${ }^{13} \mathrm{C} \mathrm{NMR}\left(100 \mathrm{MHz}, \mathrm{CDCl}_{3}\right) \delta 199.9,143.7,137.8,136.8,129.9,127.2,115.6,98.4,97.6,81.1,58.8$, 43.0, 37.1, 31.8, 31.0, 30.3, 21.6.

\section{2-But-3-enyl-1-(toluene-4-sulfonyl)-3-azepyne dicobalt hexacarbonyl complex (40). A 25-mL}

flask containing cobalt-complexed alkyne 39 (135 $\mathrm{mg}, 0.22 \mathrm{mmol}, 1.0$ equiv) was equipped with a rubber septum and gas inlet needle. Dichloromethane $(14 \mathrm{~mL})$ was added, the reaction flask was cooled at $0{ }^{\circ} \mathrm{C}$, and boron trifluoride diethyl etherate $(27 \mu \mathrm{L}, 0.22 \mathrm{mmol}, 1.0$ equiv) was added. The reaction was stirred at $0{ }^{\circ} \mathrm{C}$ for $1.5 \mathrm{~h}$ then quenched by addition of $20 \mathrm{~mL}$ saturated sodium bicarbonate. The organic layer was removed and the aqueous layer was extracted twice with dichloromethane. The combined organic layers were dried with magnesium sulfate and added to a sintered glass funnel filled with silica gel and eluted with 5-20\% diethyl ether in petroleum ether until the solution ran clear and concentration afforded $93 \mathrm{mg}(73 \%)$ of 40 as a dark red oil: ${ }^{1} \mathrm{H}$ NMR $\left(400 \mathrm{MHz}, \mathrm{CDCl}_{3}\right) \delta 7.71(\mathrm{~d}, J=$ $8.4 \mathrm{~Hz}, 2 \mathrm{H}), 7.29(\mathrm{~d}, J=8.1 \mathrm{~Hz}, 2 \mathrm{H}), 5.58(\mathrm{~m}, 1 \mathrm{H}), 5.19(\mathrm{t}, J=7.3 \mathrm{~Hz}, 1 \mathrm{H}), 4.91(\mathrm{~m}, 2 \mathrm{H}), 4.05(\mathrm{~m}, 1 \mathrm{H})$, $3.71(\mathrm{~m}, 1 \mathrm{H}), 3.26(\mathrm{~m}, 1 \mathrm{H}), 2.97(\mathrm{~m}, 1 \mathrm{H}), 2.79(\mathrm{~m}, 1 \mathrm{H}), 2.41(\mathrm{~s}, 3 \mathrm{H}), 2.04(\mathrm{~m}, 2 \mathrm{H}), 1.90(\mathrm{~m}, 1 \mathrm{H}), 1.78$ $(\mathrm{m}, 1 \mathrm{H}), 1.64(\mathrm{~m}, 1 \mathrm{H}), 1.34(\mathrm{~m}, 1 \mathrm{H}) ;{ }^{13} \mathrm{C} \mathrm{NMR}\left(100 \mathrm{MHz}, \mathrm{CDCl}_{3}\right) \delta 199.9,143.3,138.8,136.8,129.7$, $126.9,115.7,110.0,98.6,59.8,45.3,34.8,34.3,31.3,30.1,21.6$.

\section{1-Tosyl-1,2,3,4,6a,7,8,8a-octahydropentaleno[1,6-bc]azepin-5(6H)-one (42).}

Cyclohexylamine: ${ }^{17}$ A 20-mL round-bottomed flask containing Nicholas product 40 (93 mg, 0.16 mmol, 1.0 equiv) was equipped with a rubber septum and gas inlet needle. 1,2-Dimethoxyethane (5.5 $\mathrm{mL})$ was added followed by cyclohexylamine $(27 \mu \mathrm{L}, 0.24 \mathrm{mmol}, 1.5$ equiv). The rubber septum was replaced with a reflux condenser and gas inlet adapter and the reaction was heated at $60{ }^{\circ} \mathrm{C}$ for $3 \mathrm{~h}$. The heat was removed and the reaction was allowed to stir over night. The reaction mixture was added to a sintered glass funnel filled with celite and washed with ethyl acetate $(50 \mathrm{~mL})$ to yield $59 \mathrm{mg}(113 \%)$ of a 
yellow oil. The crude product was applied directly to a 6 g silica gel column and eluted with $30 \%$ diethyl ether in petroleum ether to yield $51 \mathrm{mg}(98 \%)$ of $\mathbf{4 2}$ as a colorless viscous oil: ${ }^{1} \mathrm{H}$ NMR (400 $\left.\mathrm{MHz}, \mathrm{CDCl}_{3}\right) \delta 7.71(\mathrm{~d}, J=8.4 \mathrm{~Hz}, 2 \mathrm{H}), 7.28(\mathrm{~d}, \mathrm{~J}=8.1 \mathrm{~Hz}, 2 \mathrm{H}), 5.17(\mathrm{t}, \mathrm{J}=8.4 \mathrm{~Hz}, 1 \mathrm{H}), 3.70(\mathrm{dt}, J=$ 15.4, 3.7 Hz, 1H), $2.91(\mathrm{~m}, 1 \mathrm{H}), 2.81(\mathrm{~m}, 1 \mathrm{H}), 2.65(\mathrm{dd}, \mathrm{J}=18.3,6.6 \mathrm{~Hz}, 1 \mathrm{H}), 2.40(\mathrm{~s}, 3 \mathrm{H}), 2.35-2.17$ $(\mathrm{m}, 4 \mathrm{H}), 2.06(\mathrm{dd}, \mathrm{J}=18.7,2.2 \mathrm{~Hz}, 1 \mathrm{H}), 1.88(\mathrm{~m}, 1 \mathrm{H}), 1.71(\mathrm{~m}, 2 \mathrm{H}), 1.26(\mathrm{~m}, 1 \mathrm{H}) ;{ }^{13} \mathrm{C}$ NMR $(100$ $\left.\mathrm{MHz}, \mathrm{CDCl}_{3}\right) \delta 209.1,178.7,143.5,137.8,135.7,129.9,127.1,57.9,43.7,42.6,38.9,31.6,29.9,26.6$, 21.6, 18.8; HRMS-FAB $m / z$ [M-H] ${ }^{+}$calcd for $\mathrm{C}_{18} \mathrm{H}_{20} \mathrm{NO}_{3} \mathrm{~S} 330.1164$, found 330.1153 .

\section{8-Methoxydodec-11-en-6-ynoic acid. ${ }^{27,28}$ A 25-mL two-necked flask equipped with a rubber septum} and gas inlet adapter was charged with Dess-Martin periodinane (520 mg, $1.23 \mathrm{mmol}, 1.2$ equiv) and dichloromethane (4.5 mL). A separate 25-mL pear flask containing alcohol $24(215 \mathrm{mg}, 1.02 \mathrm{mmol}, 1.0$ equiv) in $1.0 \mathrm{~mL}$ dichloromethane was cannulated into the reaction flask followed by a dichloromethane $(0.5 \mathrm{~mL})$ rinse. The reaction mixture was stirred at room temperature for $1 \mathrm{~h}$, diluted with $15 \mathrm{~mL}$ diethyl ether, and transferred to an Erlenmeyer flask containing $15 \mathrm{~mL}$ of a saturated sodium bicarbonate solution and $3 \mathrm{~g}$ of sodium thiosulfate, and stirred for $5 \mathrm{~min}$. The organic layer was washed with $50 \mathrm{~mL}$ of saturated sodium bicarbonate, $50 \mathrm{~mL}$ of water, dried with magnesium sulfate, filtered, and concentrated to yield $176 \mathrm{mg}$ (83\%) of the desired aldehyde as a yellow oil: IR (neat) 3076, 2937, 2863, 2821, 2721, 2227, 1725, $1641 \mathrm{~cm}^{-1} ;{ }^{1} \mathrm{H}$ NMR (400 MHz, $\left.\mathrm{CDCl}_{3}\right) 9.77$ (m, 1H), 5.81 (ddt, $J=17.0,10.4$, $6.6 \mathrm{~Hz} 1 \mathrm{H}), 5.03(\mathrm{dd}, J=17.2,1.5 \mathrm{~Hz}, 1 \mathrm{H}), 4.95(\mathrm{dd}, J=10.2,1.1 \mathrm{~Hz}, 1 \mathrm{H}), 3.92(\mathrm{tt}, J=6.6,1.8 \mathrm{~Hz}$, $1 \mathrm{H}), 3.38(\mathrm{~s}, 3 \mathrm{H}), 2.46(\mathrm{td}, J=7.3,1.6 \mathrm{~Hz}, 2 \mathrm{H}), 2.26(\mathrm{td}, J=7.0,1.5 \mathrm{~Hz}, 2 \mathrm{H}), 2.18(\mathrm{q}, J=7.3 \mathrm{~Hz}, 2 \mathrm{H})$, $1.76(\mathrm{~m}, 4 \mathrm{H}), 1.56(\mathrm{~m}, 2 \mathrm{H}) ;{ }^{13} \mathrm{C} \mathrm{NMR}\left(100 \mathrm{MHz}, \mathrm{CDCl}_{3}\right) \delta 202.3,137.8,115.0,85.7,79.2,70.8,56.2$, 43.3, 35.0, 29.5, 28.1, 21.2, 18.5; HRMS-FAB m/z $[\mathrm{M}-\mathrm{H}]^{+}$calcd for $\mathrm{C}_{13} \mathrm{H}_{19} \mathrm{O}_{2} 207.1385$, found 207.1404.

A $50-\mathrm{mL}$ round-bottomed flask containing the previous prepared aldehyde $(123 \mathrm{mg}, 0.59 \mathrm{mmol}, 1.0$ equiv) was equipped with a rubber septum and gas inlet needle. Dimethylformamide $(7 \mathrm{~mL})$ was added followed by Oxone (363 mg, $0.59 \mathrm{mmol}, 1.0$ equiv) and the reaction was stirred at room temperature for 
two hours. The reaction mixture was added to a separatory funnel containing ethyl acetate $(30 \mathrm{~mL})$ and 1.0 $\mathrm{M}$ hydrochloric acid $(30 \mathrm{~mL})$. The aqueous layer was removed and extracted with $50 \mathrm{~mL}$ ethyl acetate, and the combined organic layers were washed with $1.0 \mathrm{M}$ hydrochloric acid $(5 \times 50 \mathrm{~mL})$ and brine $(50 \mathrm{~mL})$, dried with magnesium sulfate, filtered, and concentrated to yield $143 \mathrm{mg}(108 \%)$ of the desired carboxylic acid as a yellow oil that was used without further purification: IR (neat) 3077, 2937, 2867, 2650, 2230, 1711, 1648, $\mathrm{cm}^{-1} ;{ }^{1} \mathrm{H}$ NMR (400 MHz, $\left.\mathrm{CDCl}_{3}\right) \delta 5.81$ (ddt, $J=17.2,10.2,6.6 \mathrm{~Hz}$, 1H), $5.04(\mathrm{dq}, J=17.0,1.8 \mathrm{~Hz}, 1 \mathrm{H}), 4.97(\mathrm{dm}, J=11.0 \mathrm{~Hz}, 1 \mathrm{H}), 3.92(\mathrm{tt}, J=6.6,1.8 \mathrm{~Hz}, 1 \mathrm{H}), 3.38(\mathrm{~s}$, 3H), $2.94(\mathrm{~d}, J=30.4 \mathrm{~Hz}, 3 \mathrm{H}), 2.38(\mathrm{t}, J=7.5 \mathrm{~Hz}, 2 \mathrm{H}), 2.26(\mathrm{td}, J=7.0,1.9 \mathrm{~Hz}, 2 \mathrm{H}), 2.20(\mathrm{~m}, 2 \mathrm{H})$, $1.76(\mathrm{~m}, 4 \mathrm{H}), 1.57(\mathrm{~m}, 2 \mathrm{H}) ;{ }^{13} \mathrm{C} \mathrm{NMR}\left(100 \mathrm{MHz}, \mathrm{CDCl}_{3}\right) \delta 179.1,137.9,115.1,85.9,79.1,70.8,56.2$, 35.0, 33.6, 29.5, 28.1, 23.9, 18.5; HRMS-FAB $m / z[M-H]^{+}$calcd for $\mathrm{C}_{13} \mathrm{H}_{19} \mathrm{O}_{3}$ 223.1334, found 223.1351.

8-Methoxydodec-11-en-6-ynoic acid dicobalt hexacarbonyl complex (61). According to the general procedure, combination of the carboxylic acid resulting from oxidation of alcohol 24 (52 $\mathrm{mg}, 0.23$ mmol, 1.0 equiv), dichloromethane $(1 \mathrm{~mL})$, and dicobalt octacarbonyl (95 mg, $0.28 \mathrm{mmol}, 1.2$ equiv then $31 \mathrm{mg}, 0.09 \mathrm{mmol}, 0.4$ equiv) followed by direct addition to a $12 \mathrm{~g}$ silica gel column and eluted with $15-100 \%$ diethyl ether in petroleum ether yielded $62 \mathrm{mg}(52 \%)$ of 61 as a dark red oil: ${ }^{1} \mathrm{H}$ NMR $\left(400 \mathrm{MHz}, \mathrm{CDCl}_{3}\right) \delta 10.8(\mathrm{br} \mathrm{s}, 1 \mathrm{H}), 5.85(\mathrm{~m}, 1 \mathrm{H}), 5.05(\mathrm{~m}, 2 \mathrm{H}), 4.27(\mathrm{~m}, 1 \mathrm{H}), 3.48(\mathrm{~s}, 3 \mathrm{H}), 2.86(\mathrm{br} \mathrm{s}$, 2H), $2.26(\mathrm{~m}, 2 \mathrm{H}), 1.79(\mathrm{~m}, 6 \mathrm{H}), 1.28(\mathrm{~m}, 2 \mathrm{H}) ;{ }^{13} \mathrm{C}$ NMR $\left(100 \mathrm{MHz}, \mathrm{CDCl}_{3}\right) \delta 200.1,137.8,115.5$, $98.3,81.1,67.0,58.8,37.1,33.7,30.4,22.4,15.3,14.2$.

\section{9,18-Dibut-3-enyl-1,10-dioxacyclooctadeca-7,16-diyne-2,11-dione dicobalt hexacarbonyl}

complex (62). According to the general procedure, combination of cobalt-complexed alkyne 61 (62 $\mathrm{mg}$, $0.12 \mathrm{mmol}, 1.0$ equiv), dichloromethane $(6 \mathrm{~mL})$, and tetrafluoroboric acid $(54 \%$ in diethyl ether, $17 \mu \mathrm{L}$, $0.12 \mathrm{mmol}, 1.0$ equiv) at $0{ }^{\circ} \mathrm{C}$ for $1 \mathrm{~h}$ followed by the aqueous workup and addition to a sintered glass funnel filled with silica gel and eluted with $10 \%$ diethyl ether in petroleum ether until the solution ran clear and concentration afforded $10 \mathrm{mg}(9 \%)$ of 62 as a dark red oil: ${ }^{1} \mathrm{H}$ NMR (400 $\left.\mathrm{MHz}, \mathrm{CDCl}_{3}\right) \delta 6.03$ 
$(\mathrm{m}, 2 \mathrm{H}), 5.84(\mathrm{~m}, 2 \mathrm{H}), 5.03(\mathrm{~m}, 4 \mathrm{H}), 2.80(\mathrm{~m}, 4 \mathrm{H}), 2.55-2.19(\mathrm{~m}, 6 \mathrm{H}), 2.01-1.54(\mathrm{~m}, 14 \mathrm{H}) ;{ }^{13} \mathrm{C} \mathrm{NMR}$

$\left(100 \mathrm{MHz}, \mathrm{CDCl}_{3}\right) \delta 199.7,172.5,137.1,125.6,115.7,99.3,72.8,35.8,34.3,33.3,31.5,30.2,25.2$.

Acknowledgment. We thank Research Corporation and Smith College for generous financial support. M.M.Q. would like to thank Pfizer for a summer undergraduate research fellowship. We thank Amanda Freeman and Kate Whitesell for investigating the use of chiral amine promoters in the PausonKhand reaction. We thank the reviewers for helpful suggestions to improve the clarity and overall quality of this manuscript. We thank Dr. Charles Amass (Smith College) for assistance with NMR experiments, Dr. Mohini Kulp (Smith College) and the Center for Proteomics for assistance with MS experiments, and Dr. Stephen J. Eyles (University of Massachusetts, Amherst) and the University of Massachusetts Mass Spectrometry Facility which is supported, in part, by the National Science Foundation for assistance with HRMS experiments.

Supporting Information Available. General experimental details, materials, references to compounds previously reported in the literature, experimental procedures for all new compounds, $1 \mathrm{D}{ }^{1} \mathrm{H}$

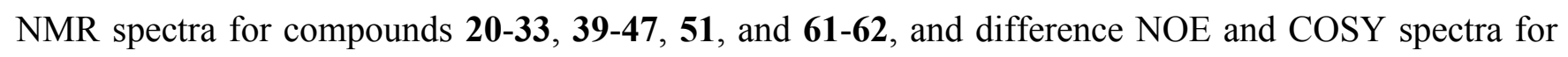
27, 28, 42. This material is available free of charge via the Internet at http://pubs.acs.org.

\section{References.}

${ }^{1}$ For a review, see Aubert, C.; Fensterbank, L.; Gandon, V.; Malacria, M. Topics in Organometallic Chemistry 2006, 19, 259-294.

2 For a review of tandem Nicholas/Pauson-Khand reactions, see Pérez-Castells, J. Topics in Organometallic Chemistry 2006, 19, 207-257.

3 a) Jamison, T. F.; Shambayati, S.; Crowe, W. E.; Schreiber, S. L. J. Am. Chem. Soc. 1997, 119, 43534363. b) Jamison, T. F.; Shambayati, S.; Crowe, W. E.; Schreiber, S. L. J. Am. Chem. Soc. 1994, 116, 5505-5506.

${ }^{4}$ For preliminary reports from our lab, see a) Quintal, M. M.; Closser, K. D.; Shea, K. M. Org. Lett. 2004, 6, 4949-4952. b) Shea, K. M.; Closser, K. D.; Quintal, M. M. J. Org. Chem. 2005, 70, 9088-9091.

5 For reviews, see a) Shea, K. M. In Name Reactions for Homologations-1; Li, J. J., Ed.; Wiley: Hoboken, NJ 2009; pp 284-298. b) Diaz, D. D.; Betancort, J. M.; Martin, V. S. Synlett 2007, 343-359. c) Teobald, B. J. Tetrahedron 2002, 58, 4133-4170. 
${ }^{6}$ Sly, W. G. J. Am. Chem. Soc. 1959, 81, 18-20.

7 a) Iwasawa, N.; Inaba, K.; Nakayama, S.; Aoki, M. Angew. Chem. Int. Ed. 2005, 44, 7447-7450. b) Yang, Z.-Q.; Geng, X.; Solit, D.; Pratilas, C. A.; Rosen, N.; Danishefsky, S. J. J. Am. Chem. Soc. 2004, $126,7881-7889$.

${ }^{8}$ Hamajima, A.; Isobe, M. Org. Lett. 2006, 8, 1205-1208.

${ }^{9}$ For a communication from our lab containing several examples of endocyclic intramolecular Nicholas reactions with alcohol nucleophiles, see reference $4 \mathrm{a}$.

10 For examples of intermolecular and exocyclic intramolecular Nicholas reactions with amine nucleophiles, see a) Hernández, J. N.; Ramírez, M. A.; Rodríguez, M. L.; Martín, V. S. Org. Lett. 2008, 10, 2349-2352. b) Roy, S. K.; Basak, A. Chem. Commun. 2006, 1646-1648. c) Roth, K. D.; Mueller, U. Tetrahedron Lett. 1993, 34, 2919-2922.

${ }^{11}$ Betancort, J. M.; Rodriguez, C. M.; Martin, V. S. Tetrahedron Lett. 1998, 39, 9773-9776.

12 For a preliminary report from our lab detailing inter- and intramolecular Nicholas reactions with carboxylic acid nucleophiles, see reference $4 \mathrm{~b}$.

${ }^{13}$ For reviews, see a) Strübing, D.; Beller, M. Topics in Organometallic Chemistry 2006, 18, 165-178. b) Laschat, S.; Becheanu, A.; Bell, T.; Baro, A. Synlett 2005, 2547-2570. c) Brummond, K. M.; Kent, J. L. Tetrahedron 2000, 56, 3263-3283.

${ }^{14}$ For a review of cyclic cobalt-complexed alkynes, see Green, J. R. Cur. Org. Chem. 2001, 5, 809-826.

15 a) Liu, T.-Z.; Li, J.-M.; Isobe, M. Tetrahedron 2000, 56, 10209-10219. b) Yenjai, C.; Isobe, M. Tetrahedron 1998, 54, 2509-2520.

${ }^{16}$ Shambayati, S.; Crowe, W. E.; Schreiber, S. L. Tetrahedron Lett. 1990, 31, 5289-5292.

${ }^{17}$ Sugihara, T.; Yamada, M.; Ban, H.; Yamaguchi, M.; Kaneko, C. Angew. Chem. Int. Ed. 1997, 36, 2801-2804.

${ }^{18}$ The diastereomeric ratios for all Pauson-Khand products were determined by ${ }^{1} \mathrm{H}$ NMR. Major and minor isomers were assigned using COSY and difference NOE NMR experiments.

${ }^{19}$ Results for all of the Pauson-Khand conditions are available in reference $4 \mathrm{a}$.

${ }^{20}$ Denmark, S. E.; Yang, S.-M. J. Am. Chem. Soc. 2002, 124, 2102-2103.

${ }^{21}$ This is a known compound, see Marino, J. P.; Nguyen, H. N. J. Org. Chem. 2002, 67, 6291-6296.

${ }^{22}$ Suhihara, T.; Yamada, M.; Yamaguchi, M.; Nishizawa, M. Synlett 1999, 771-773.

${ }^{23}$ For a review, see Hughes, D. L. Org. Prep. Proced. Int. 1996, 28, 127-164.

${ }^{24}$ Bach, T.; Kather, K. J. Org. Chem. 1996, 61, 7642-7643.

${ }^{25}$ Valle, C. P. d.; Milet, A.; Gimbert, Y.; Greene, A. E. Angew. Chem. Int. Ed. 2005, 44, 5717-5719.

${ }^{26}$ a) Kerr, W. J.; Lindsay, D. M.; Rankin, E. M.; Scott, J. S.; Watson, S. P. Tetrahedron Lett. 2000, 41, 3229-3233. b) Derdau, V.; Laschat, S.; Jones, P. G. Heterocycles 1998, 48, 1445-1448.

${ }^{27}$ Dess, D. B.; Martin, J. C. J. Am. Chem. Soc. 1991, 113, 7277-7287. 
${ }^{28}$ Travis, B. R.; Sivakumar, M.; Hollist, G. O.; Borhan, B. Org. Lett. 2003, 5, 1031-1034.

29 The structure of cobalt-alkyne complex $\mathbf{5 5}$ was not unambiguously assigned by NMR spectroscopy because the material was used immediately in the subsequent Nicholas reaction. Due to the similarity in TLC behavior to all of the other cobalt-alkyne complexes prepared in our lab, we are confident that 55 was successfully synthesized.

30 The structure of diolide $\mathbf{5 6}$ could not be unambiguously assigned by NMR spectroscopy due to the presence of paramagnetic cobalt impurities even after purification by column chromatography. We are confident in the formation of this compound due to the similar TLC behavior and general ${ }^{1} \mathrm{H}$ NMR features (very broad peaks) in comparison to diolides 59 and 62.

31 The structure of the trans isomer of $\mathbf{5 9}$ was confirmed by X-ray single crystal analysis; see reference $4 \mathrm{~b}$.

32 (a) Christoffers, J.; Oertling, H.; Fischer, P.; Frey, W. Tetrahedron 2003, 59, 3769-3778. (b) Shiina, I.; Mukaiyama, T. Chem. Lett. 1994, 677-680. (c) Mukaiyama, T.; Izumi, J.; Miyashita, M.; Shiina, I. Chem. Lett. 1993, 907-910. (d) White, J. D.; Green, N. J.; Fleming, F. F. Tetrahedron Lett. 1993, 34, 3515-3518.

${ }^{33}$ For procedures that minimize or eliminate diolide formation, see: (a) Kinoshita, H.; Shinokubo, H.; Oshima, K. Angew. Chem. Int. Ed. 2005, 44, 2397-2400. (b) Molander, G. A.; Dehmel, F. J. Am. Chem. Soc. 2004, 126, 10313-10318. (c) Ashfeld, B. L.; Miller, K. A.; Martin, S. F. Org. Lett. 2004, 6, 1321 1324. (d) Ishihara, K.; Kubota, M.; Kurihara, H.; Yamamoto, H. J. Org. Chem. 1996, 61, 4560-4567. 